\title{
Winter-time dependence of the global TEC on the stratospheric temperature and solar radiation
}

\author{
Plamen Mukhtarov* and Dora Pancheva
}

\begin{abstract}
National Institute of Geophysics, Geodesy and Geography, Bulgarian Academy of Sciences, Acad. G. Bonchev Str., B1. 3, 1113 Sofia, Bulgaria
\end{abstract}

\begin{abstract}
This paper presents a simple linear regression model that enables to quantify the contribution of high-latitude stratospheric temperature and solar radiation (describes by its proxy F10.7) to the variability of the low-latitude TEC during winter. The model is based on cross-correlation analysis performed on the Aura MLS temperature measurements and the global CODE TEC data for the period of time 2005-2010, i.e. at low to moderate solar activity (F10.7 changes between $\sim 65$ and $\sim 140$ solar flux units). It revealed that the temperature at altitude of $\sim 40 \mathrm{~km}$ and latitude of $\sim 60^{\circ} \mathrm{N}$ describes the most typical winter conditions and shows the largest negative correlation with the low-latitude TEC. This temperature namely is included in the regression model. The model results have been compared with the TEC data by calculating the standard deviation (STD). The comparison indicated that the regression model describes almost half of the real variability of the global TEC and that the contribution of the temperature (that is only a part of forcing from below) is almost half of the solar variability (i.e. external forcing related to the photo-ionization). A possible mechanism for explaining the relationship between the high-latitude stratospheric increase of the temperature and low-latitude decrease of the TEC is suggested.
\end{abstract}

Key words: atmosphere-ionosphere coupling, stratospheric temperature, TEC, tides, neutral composition changes

* Corresponding author: Plamen Mukhtarov, e-mail: engpjm@abv.bg 


\section{Introduction}

The atmosphere-ionosphere system is a strongly coupled system in which events occurring at lower atmosphere can have impact on the ionosphere. The phenomenon sudden stratospheric warming (SSW) is the clearest and strongest manifestation of this coupling with consequences even for weather (Baldwin and Dunkerton, 2001). The SSW is a dramatic meteorological event in the polar stratosphere during which the temperature rapidly increases by several tens of Kelvins only in a few days and then recovers over a period of a few weeks. Now it is widely accepted that SSW events are brought about by propagating upward enhanced stationary planetary waves (SPWs) which interact with the zonal mean flow (Matsuno, 1971; Andrews et al., 1987). The interaction decelerates and/or reverses the eastward winter winds and also induces a downward circulation in the stratosphere, causing adiabatic heating. There may also be an upward circulation in the mesosphere, causing adiabatic cooling (Liu and Roble, 2002). It is well known now that there exist SSWs with polar vortex splitting, i.e. "a vortex-split" type, along with those known as "a vortex-displacement" type (Charlton and Polvani, 2007). Many studies have shown that the amplification of SPW of zonal number 2 (SPW2) plays more important role in generating of "a vortex-split" type while "a vortexdisplacement" type SSW is forced mainly by the amplification of SPW1 (McIntyre, 1982; Krüger et al., 2005; Iida et al., 2014).

Recently the interest to SSW events in the context of atmosphere-ionosphere coupling significantly increased. The studies in this direction have been accelerated mainly due to: (a) occurrence of unusually strong and prolonged SSW events; (b) solar and geomagnetic minimum conditions, particularly between 2007 and 2010, and (c) the existence of satellite observations of the atmosphere-ionosphere system which provide global measurements. Some incoherent scatter radar and Fabry-Perot observations at middle and high latitudes shed some light on the SSW response of the thermosphere as well. They identified large perturbations of ion and neutral temperatures at heights above $100 \mathrm{~km}$ revealing some increase of temperature in the height range of 100-140 km and its decrease above $150 \mathrm{~km}$ (Goncharenko and Zhang, 2008; Conde and Nicolls, 2010; Kurihara et al., 2010). Nevertheless that the above mentioned neutral temperature changes have been observed at single stations (Millstone Hill, Poker Flat and ESCAT) they supported to some extent the result obtained from the global circulation model reported by Liu and Roble (2002). This model predicted that the stratospheric warming is accompanied by both mesospheric cooling and lower thermospheric warming. The model result however is addressed to the zonal mean temperature, not to the temperature at a fixed geographic point, and it has been later confirmed by the satellite measurements of the instrument MIPAS on the satellite ENVISAT during the major SSW event in January 2009 (Funke et al., 2010). Liu et al. (2011) reported later upper thermosphere cooling in the predawn and pre-sunset sector simultaneously observed by CHAMP and GRACE satellites during the same event. The ionosphere electrodynamic changes during SSW events have been also widely reported indicating enhanced semidiurnal variability of the vertical plasma drift (Chau et al., 2009; Goncharenko et al., 2010a; 2010b). The local time and altitude dependence of the thermospheric temperature and density response simulated by the whole atmosphere GAIA model has been reported in Liu et al. (2013). The study revealed that the effect is primarily quasi-semidiurnal in tropical regions, and is apparently driven by the same tides that cause the semidiurnal variability of the vertical plasma drift, i.e. of the ionosphere.

Atmospheric tides are generated by diurnal cycling of solar heating of the troposphere and stratosphere, latent heat release in the troposphere and nonlinear interaction between different tidal components and planetary waves. The spatial and temporal variability of the tidal amplitudes and phases depends on variability of their sources and background conditions for their propagations. The frequency-wave number decomposition method has been commonly 
used in the lower and middle atmosphere for deriving the tidal characteristics. The satellite measurements have shown that many of the atmospheric tides are capable to propagate deep into the mesosphere and lower thermosphere (MLT) (Forbes et al., 2008), where have the potential to influence ionospheric variability via dynamo effects. Although ionospheric features may also be decomposed into tidal components by a method analogous to that used in the middle atmosphere, early studies on atmosphere/ionosphere coupling relied on a method conventional in ionospheric studies where spatial variability is examined in a constant local time reference frame (Chang et al., 2013). Some of the first studies to extend tidal analysis to the ionosphere were those of Mukhtarov and Pancheva (2011), Pancheva and Mukhtarov (2012a) and Pancheva et al.(2012). They used the commonly employed tidal method for retrieving of specific tidal components not only from temperatures measured by the SABER instrument on board of the TIMED satellite but also from electron densities measured by the satellite system FORMOSAT-3/COSMIC. It is worth noting that by applying the frequencywave number decomposition method on ionospheric parameters their spatial variability is examined in a constant universal time reference frame. In this way it is possible to separate the zonal mean state of the ionosphere from different wave variations (we remind that when the spatial variability is examined in a constant local time reference frame then the migrating tidal features are aliased into zonal mean values, and nonmigrating tides are aliased into stationary planetary waves). We clarify that the term "zonal mean" refers to averages over both longitudes and times when the satellite measurements are analyzed.

One of the first results demonstrating how the ionospheric plasma reacts on the SSW is obtained by Pancheva and Mukhtarov (2011). The authors analyzed the electron density profiles in the height range of 100-800 km measured by the satellite system FORMOSAT3/COSMIC during the winters 2007/2008 and 2008/2009. For each latitude and altitude the electron density time series were decomposed to zonal mean values and different tides and planetary waves. It has been found that both zonal mean and diurnal migrating variability of the electron density decrease during the peak of the considered SSW events. Later the result for the major SSW in January 2009 was confirmed by Lin et al. (2012) and Oyama et al. (2014). Pancheva and Mukhtarov (2011) suggested also a possible physical mechanism that could lead to a decrease of the zonal mean electron density. It was analogous to the so called "disturbed dynamo" (Blanc and Richmond, 1980), however in this case the disturbed dynamo is a current system driven by the equatorward lower thermospheric winds forced at high latitudes because of thermospheric SSW heating. This mechanism has been confirmed later by numerical simulations with the Global Self-consistent Model of Thermosphere, Ionosphere, and Protonosphere (GSM TIP) presented by Korenkov et al. (2012) and by observations showing a systematic enhancement in the oxygen dayglow emission intensities measured at low-latitude stations during four SSW events occurring in the years 2010-2013. The latter has been explained by transport of atomic oxygen from high-to-low latitudes (Laskar and Pallamraju, 2014). Very recently Liu et al. (2014) have studied the thermal and dynamical changes of the zonal mean state of the thermosphere during the major SSW in January 2009 by simulations with the GAIA model. The authors showed that the zonal mean zonal wind experiences a strong westward perturbation in the tropical thermosphere, a result that also partly supports the suggested by Pancheva and Mukhtarov (2011) physical mechanism.

It has been already mentioned that Goncharenko et al., (2010a; 2010b) first observed enhanced semidiurnal variability of the vertical plasma drift and TEC measurements at fixed geographical locations. The single station observations however contain too complex information, i.e. such observations do not allow resolving migrating from nonmigrating components and defining their zonal structures. This weak point of ground-based 
measurements can be overcome by satellite observations that give global coverage data. This has been done by Pedatella and Forbes (2010) on the base of TEC observations of the Global Positioning System (GPS) and Pancheva and Mukhtarov (2012b) by analyzing the COSMIC electron density. The above mentioned studies reported significant amplification of both migrating and nonmigrating semidiurnal variabilities of the ionospheric plasma in the low latitudes after the peak of the major SSW in January 2009. Pancheva and Mukhtarov (2012b) presented even evidence showing that the concurrent presence of migrating and nonmigrating components can explain the observed phase variability of the 12-h oscillation seen in the TEC measurements made at a single point and reported by Goncharenko et al (2010b). The first detailed comparison between the simulated results obtained by the Whole AtmosphereIonosphere Coupled Model, known as the GAIA model, and the analyzed satellite measurements of the SABER temperature and COSMIC electron density during the major SSW in January 2009, is reported by Jin et al. (2012). This study demonstrated not only very good agreement in the major features from the stratosphere to the ionosphere shown by the model and satellite observations but also indicated that the ionospheric response to the considered SSW is forced predominantly by the strongly amplified migrating semidiurnal tide (noted as SW2) in the MLT region that affects the ionosphere via the modulated vertical plasma drift. The tidal amplification is caused by the favorable background conditions for vertical propagation of the SW2 tide which have been changed due to the SSW.

The above mentioned results clearly indicate a global change response of the thermosphereionosphere system to SSW events, in spite of the fact that SSW is a high-latitude phenomenon which occurred much below the height region of thermosphere. Furthermore, the strongest response of the ionosphere according to the observations and simulations is at low-latitude region. The results of Pancheva and Mukhtarov (2011), particularly for the winter 2007/2008, have provided additional evidence for the atmosphere-ionosphere coupling during winter. It has been found a regular decrease of the low-latitude zonal mean electron density to each temperature peak in the high-latitude stratosphere (at $60^{\circ} \mathrm{N}$ and at pressure level of $10 \mathrm{hPa}$ ) with a duration close to the used window for analysis of COSMIC data (16 days), emphasizing that not all of the temperature peaks have been related to SSW events (see the left column of Figure 1 in Pancheva and Mukhtarov (2011)). This finding has directed our attention to a possible relationship between the variability of the low-latitude electron density and that of the high-latitude stratospheric temperature during winter. Due to this the next step is to conduct a detailed research on the low-latitude ionosphere - high-latitude stratospheric temperature coupling, observed in winter during low to moderate solar activity, and to present an idea for a possible mechanism defining this coupling. This is actually the basic aim of the present study. For this purpose we analyze the global TEC data from the Center for Orbit Determination of Europe (CODE) which determine the ionospheric variability and temperature measurements from the Aura Microwave Limb Sounder (MLS) instrument characterizing the variability of the middle atmosphere. An attempt is made to quantify the contribution of the stratospheric temperature impact to the TEC variability comparing it with that of the solar activity influence. In the present study the solar radio flux at $10.7 \mathrm{~cm}$ wavelength (F10.7) is used as a proxy for the solar activity. Only the data set for the period of time 2005-2010 that is characterized by low to moderate solar activity when F10.7 changes between $\sim 65$ and $\sim 140$ solar flux units $\left(10^{-22} \mathrm{~W} \mathrm{~m}^{-2} \mathrm{~Hz}^{-1}\right)$.

\section{Used data and methods for data analysis}

Global observations of temperature and geopotential height from the MLS instrument onboard the NASA EOS Aura satellite, launched July 15, 2004, are used in this study. Aura 
MLS is a limb scanning emission microwave radiometer which measures radiation in five spectral regions from $115 \mathrm{GHz}$ to $2.5 \mathrm{THz}$. The Aura satellite has sun-synchronous polar orbit that allows nearly pole-to-pole coverage (a latitude range from $-82^{\circ}$ to $82^{\circ}$ ) on each orbit and measurements made in the orbit plane that enables more accurate handling of atmospheric gradients in the line-of-sight direction. The temperature and geopotential height measurements are taken from observations near the 118- $\mathrm{GHz} \mathrm{O} \mathrm{O}_{2}$ spectral line and the 234$\mathrm{GHz} \mathrm{O}{ }^{18} \mathrm{O}$ spectral line (Schwartz et al., 2008). MLS looks forward from the Aura spacecraft and scans the Earth's limb vertically every $24.7 \mathrm{~s}$. The MLS vertical scans are synchronized to the Aura orbit such that vertical scans are made at essentially the same latitudes each orbit, with 240 scans performed per orbit ( $\sim 3500$ scans per day).

The temperature data used in this paper are retrieved from calibrated MLS limb radiances using MLS version 2.2, level-2 software (Livesey et al., 2008) and are downloaded from http://disc.sci.gsfc.nasa.gov/Aura/data-holdings/MLS/index.shtml. The data are recorded on 34 pressure levels ranging from $316-0.001 \mathrm{hPa}(\sim 10-92 \mathrm{~km})$. Temperature precision is $\sim 1$ $\mathrm{K}$ or better from $316 \mathrm{hPa}$ to $3.16 \mathrm{hPa}$, degrading to $\sim 3 \mathrm{~K}$ at $0.001 \mathrm{hPa}$. The vertical resolution is $\sim 3 \mathrm{~km}$ at $31.6 \mathrm{hPa}$, degrading to $\sim 6 \mathrm{~km}$ at $316 \mathrm{hPa}$ and to $\sim 13 \mathrm{~km}$ at $0.001 \mathrm{hPa}$ (Schwartz et al., 2008). The computer code is devised which enables obtaining two vertical profiles of temperature over a given point depending on ascending or descending satellite orbit. In this way the Aura MLS provides daily global coverage data obtained by averaging the two measurements at each point. The temperature variations in this study are presented by daily zonal mean (ZM) values (longitude averaging) for latitudes from $-80^{\circ}$ to $80^{\circ}$ at each $5^{\circ}$ and all height levels between $\sim 10 \mathrm{~km}$ and $\sim 90 \mathrm{~km}$.

It has been already mentioned that the ionospheric variability is described by the global TEC data constructed on the base of TEC maps generated by the CODE at Astronomical and Physical Institutes of the University of Bern. The data are downloaded from the CODE FTP directory: $\mathrm{ftp}: / / \mathrm{ftp}$.unibe.ch/aiub/CODE/. The details about the generation of the CODE TEC maps can be found in Schaer (1999). The original global TEC data were arrayed in terms of the coordinate system of geographical latitude (from $-87.5^{\circ}$ to $87.5^{\circ}$ at each $2.5^{\circ}$ ) and longitude (from $-180^{\circ}$ to $180^{\circ}$ at each $5^{\circ}$ ); they have a time resolution of $2 \mathrm{~h}$. It is known however that the neutral wind and electric field effects on the ionosphere are dependent on the geomagnetic field configuration as the electrons are constrained to the magnetic field lines. That is why the distribution of the ionospheric parameters, including TEC, is usually presented in geomagnetic latitude instead of geographic one. We work with the modified dip latitude (modip), introduced by Rawer (1963). For this purpose the global TEC data were rearrayed in terms of the coordinate system of modip latitude, from $-80^{\circ}$ to $80^{\circ}$ at each $5^{\circ}$, and geographic longitude, from $-180^{\circ}$ to $180^{\circ}$ at each $15^{\circ}$. The TEC data falling into the area $5^{\circ}$ (modip latitude) $\times 15^{\circ}$ (longitude) were averaged. For each day and latitude we calculate the zonal mean (ZM) TEC as well as the amplitudes of the diurnal (DW1) and semidiurnal (SW2) TEC variations. This means that the ionospheric variability is described by the daily time series of the three most important TEC components.

This study investigates the relationship between the variability of the high-latitude stratospheric temperature and the ionospheric TEC during boreal winter (from 01 October to $31 \mathrm{March}$ ) at low to moderate solar activity (2005-2010). The relationship will be assessed by cross-correlation and regression analysis. It is known that cross-correlation depends strongly on the trends of both time series. As both temperature and TEC time series have well defined seasonal behaviour then first we have to remove the seasonal variation from the daily time series. This is done by removing from the daily values the 31-day running mean. This procedure effectively eliminates all long-lasting variations having time scales larger than a month. In this way the residual time series of the temperature and TEC can be considered as 
deviations from their seasonal courses. The analysis is done only by using the boreal winter time series (October-March) except when it is explicitly noted that the entire time interval $(2005-2010)$ is analyzed.

\section{Cross-correlation analysis results}

\subsection{Between TEC and high-latitude stratospheric temperature}

The first question we have to answer is: the stratospheric temperature around which latitude and altitude describes the most typical winter conditions. In Pancheva and Mukhtarov (2011) the temperature at latitude of $60^{\circ} \mathrm{N}$ and at geopotential height of $10 \mathrm{hPa}$ is shown but this has been done because the background temperature and zonal wind fields during the SSW are usually determined there. The answer of the above question depends on the relationship between the temperature variations at different altitudes in the range $\sim 10-90 \mathrm{~km}$ and different latitudes between $\pm 80^{\circ}$. This relationship is investigated by cross-correlation analysis done on the all winter time series between 2005 and 2010. The left column of Figure 1 shows the altitude structures of the cross-correlation functions between the temperature at $\sim 40 \mathrm{~km}$ altitude and $60^{\circ} \mathrm{N}$ with all temperatures above the equator (upper plot), at $60^{\circ} \mathrm{N}$ (middle plot) and at $80^{\circ} \mathrm{N}$ (bottom plot); the white line represents the zero cross-correlation coefficient. The time lags between \pm 30 days are shown in the horizontal axis. The following main features of the altitude structures are seen from the plots:

- The cross-correlations at one and the same latitude $\left(60^{\circ} \mathrm{N}\right.$, middle plot) are positive in the stratosphere and negative in the mesosphere where the maximum correlation of -0.5 is observed for altitude of $\sim 80-85 \mathrm{~km}$ with a time lag of 1-2 days. A careful inspection of the positive correlations in the stratosphere reveals that only at a narrow altitude range around $40 \mathrm{~km}$ the time lag is zero; below and above this range some delay is seen between the temperature variations at $\sim 40 \mathrm{~km}$ and those at altitudes above and below 40 $\mathrm{km}$.

- The cross-correlations with the stratospheric temperatures above the equator (upper plot) are negative reaching maximum coefficient of -0.7 at altitudes around $40 \mathrm{~km}$ with zero time lag; below and above this altitude some delay is seen. The cross-correlations with the mesospheric temperatures are positive but the maximum coefficients do not exceed 0.3 .

- The cross-correlations with the stratospheric temperatures at $80^{\circ} \mathrm{N}$ (bottom plot) are positive reaching maximum coefficient of +0.5 at altitudes around $40 \mathrm{~km}$ with time lag of 1-2 days; there is a slight increase of the time lag below and above $40 \mathrm{~km}$. The crosscorrelations with the mesospheric temperatures are negative with a maximum correlation of -0.5 observed around $80 \mathrm{~km}$ altitude with a time lag of 1-2 days.

The right column of plots shows the latitude structures of the cross-correlation functions between the temperature at latitude of $60^{\circ} \mathrm{N}$ and altitude of $\sim 40 \mathrm{~km}$ with the temperatures at altitudes of $\sim 82 \mathrm{~km}$ (upper plot), $\sim 40 \mathrm{~km}$ (middle plot) and $\sim 31 \mathrm{~km}$ (bottom plot). The main features of the latitude structures are to some extent hinted at the left column of plots. At altitude of $\sim 40 \mathrm{~km}$ the cross-correlation is positive at high and middle latitudes it becomes zero at tropical latitudes of $\sim 30-35^{\circ} \mathrm{N}$ and negative in the entire latitude range from $\sim 30^{\circ} \mathrm{N}$ to $\sim 70^{\circ} \mathrm{S}$. The maximum negative correlation coefficient is -0.7 with a zero time lag. An important feature is the existence of some delay at latitudes higher than $25^{\circ} \mathrm{N}$. The results for altitude of $\sim 31 \mathrm{~km}$ (bottom plot) are similar to that at $\sim 40 \mathrm{~km}$ but the cross-correlation coefficients are smaller (they range between +0.53 and -0.52) and some time lag of 1-3 days is seen. The result for the mesosphere level of $\sim 82 \mathrm{~km}$ (upper plot) is opposite to those for the 
stratosphere levels, i.e. the cross-correlation is negative at high and middle latitudes it becomes zero at tropical latitudes of $\sim 30^{\circ} \mathrm{N}$ and positive in the entire latitude range from $\sim 30^{\circ} \mathrm{N}$ to $\sim 80^{\circ} \mathrm{S}$. It is worth mentioning that Mukhtarov et al. (2007) and Shepherd et al. (2007) by investigating concrete winters but different from those considered in this paper reported similar qualitative results. The cross-correlation coefficients are not very high and change from 0.3 to -0.5 and the time lag of 2-3 days exists. We underline however that according to the "Fisher's Z-transformation" test, all above obtained coefficients are above $95 \%$ confidence level, i.e. they are significant.

There is one more signature evident at plots where the cross-correlations are calculated between temperatures at close altitudes or latitudes. Such plots are mainly the middle ones of Figure 1 and their cross-correlation functions demonstrate some periodicity of $\sim 20-25$ days around altitudes of $\sim 40 \mathrm{~km}$ and $\sim 80 \mathrm{~km}$ for the left plot and at $\sim 60^{\circ} \mathrm{N}$ and low latitudes for the right plot. This $\sim 20$-25-day periodicity reflects the presence of such zonally traveling and zonally symmetric waves in the temperature field which have distinct altitude and latitude structure (Pancheva et al., 2009).

The main conclusion from Figure 1 is that the stratospheric temperature variabilities at altitudes below and above $\sim 40 \mathrm{~km}$ height and at latitudes higher than $\sim 60^{\circ} \mathrm{N}$ demonstrate some delay with respect to those at altitude of $\sim 40 \mathrm{~km}$ and latitude of $\sim 60^{\circ} \mathrm{N}$. Hence the above analysis indicated that the temperature at altitude of $\sim 40 \mathrm{~km}$ and latitude of $\sim 60^{\circ} \mathrm{N}$ describes the most typical winter conditions and for the purpose of this study could be called a winter benchmark temperature.

The next step in our analysis is to calculate the cross-correlation functions between the winter benchmark temperature and the selected main TEC decomposed components: ZM and amplitudes of DW1 and SW2. The left column of plots in Figure 2 shows the latitude structures of the cross-correlation functions between different ZM temperatures and ZM TEC. Besides the winter benchmark temperature (upper plot) also the ZM temperatures over the equator at altitude of $\sim 40 \mathrm{~km}$ (middle plot) and at altitude of $\sim 90 \mathrm{~km}$ (bottom plot) are used. The temperatures over the equator are chosen because it is natural to presume that if the ionospheric response is the strongest at low latitudes the temperature there would have stronger impact than at other latitudes. The comparison between the three plots shows that the maximum negative correlation coefficient of -0.3 with time lag of $0-1$ day is observed with the benchmark temperature. The correlation with the ZM temperature at altitude of $\sim 90 \mathrm{~km}$ (bottom plot) is not only a weak one, only -0.12 , but the time lag is negative. This negative time lag is an indication that the temperature at $\sim 90 \mathrm{~km}$ cannot be used as a forcing of the ionospheric TEC (the response cannot precede the forcing). The right column of plots in Figure 2 shows the same as the left column results but the cross-correlation is with the DW1 TEC. The comparison between these three plots shows that the maximum negative correlation coefficient of -0.28 with a time lag of 1-2 days is found with the benchmark temperature.

The cross-correlation results with the amplitudes of SW2 are not shown because the picture is not very consistent and in general the correlation is weak. We remind that nevertheless that the obtained negative cross-correlations are not very high, -0.30 and -0.28 , they are significant, i.e. above $95 \%$ confidence level.

While the left column of plots in Figure 3 shows the altitude structure of the cross-correlation functions between $\mathrm{ZM}$ temperatures at different latitudes (at $60^{\circ} \mathrm{N}$ (upper plot), over the equator (middle plot) and at $80^{\circ} \mathrm{N}$ (bottom plot)) and ZM TEC the right one shows the same but with the amplitude of DW1 TEC. This result not only supports that in Figure 2 but clarify how the altitude range with maximum correlation is narrow one. Figure 3 provides also an additional to Figure 2 feature of the cross-correlation functions: both figures show that the 
cross-correlation functions demonstrate clear periodicity of $\sim 20-25$ days but the upper row of plots in Figure 3 reveals some downward progression of this periodicity. This is an indication for the effect of the long period zonally symmetrical waves that are present in the middle atmosphere (Pancheva et al., 2007; Pancheva et al., 2008a).

In general the cross-correlation results from Figures 2 and 3 support the observations reported by Pancheva and Mukhtarov (2011) as the largest cross-correlation coefficients between the winter benchmark temperatures with ZM TEC and DW1 TEC respectively -0.30 and -0.28 .

\subsection{Between TEC and Solar radio flux}

The main effect on the ionospheric variability however has the solar radiation represented in this study by its proxy solar radio flux F10.7. We underline that the geomagnetic effects are excluded from this study because the main object here is to present a simple linear model for assessing the contribution of the variability of the stratospheric temperature and F10.7 to the TEC variability in winter while it is known that the geomagnetic effects are nonlinear ones (Mukhtarov et al., 2013). Before finding an approximate quantitative relationship between the effects of the stratospheric temperature and F10.7 on the ionospheric TEC we apply crosscorrelation analysis to F10.7 as well. Figure 4a shows the daily values of F10.7 for the period of time 2005-2010 not only to demonstrate that the considered period of time belongs to middle and low solar activity but also to point out the presence of strong 27-day variations that can be seen almost during the entire period except the second half of 2008 and first part of 2009. Figure $4 \mathrm{~b}$ shows the latitude structure of the cross-correlation functions between F10.7 with ZM TEC (upper plot) and DW1 TEC (bottom plot). We underline that the crosscorrelation functions are calculated by using the data from the entire interval of time between January 2005 and December 2010. In general, the cross-correlations reveal already known features: (i) positive correlation between F10.7 and both TEC components with maximum correlation coefficients 0.52 and 0.45 for ZM and DW1 respectively and time lags of 1-3 days, and (ii) the impact of 27-day F10.7 variability. It is worth mentioning also that the maximum correlation is seen not only in the tropical latitudes but some amplification can be noticed also around $60^{\circ} \mathrm{N}$ for ZM TEC and around $\pm 50^{\circ}$ for DW1 TEC.

It is worth noting however that the solar radiation has some impact on the stratospheric temperatures as well. This can be demonstrated again by the cross-correlation analysis between F10.7 and stratospheric temperatures at different heights and latitudes. Figure 5a shows the altitude structure of the cross-correlation functions of F10.7 with the ZM temperatures over the equator (left plot) and at latitude of $20^{\circ} \mathrm{N}$ (right plot) while Figure $5 \mathrm{~b}$ shows the latitude structure of the cross-correlation between F10.7 and the ZM temperatures at $\mathrm{h} \sim 44 \mathrm{~km}$ (left plot) and $\mathrm{h} \sim 40 \mathrm{~km}$ (right plot). The strongest positive influence is seen at tropical region, $\pm 30^{\circ}$, and at altitudes around $45 \mathrm{~km}$ but the cross-correlation coefficients are small, ranging from 0.14 to 0.17 . We notice that the winter benchmark temperature shows a weak negative correlation (Figure 5b, right plot) with a maximum coefficient of -0.09 and a zero time lag. This means that F10.7 has insignificant effect on it. Despite the small crosscorrelation coefficients we have to keep in mind that the temperatures around $40-50 \mathrm{~km}$ height particularly at low latitudes are not completely independent on F10.7.

It is worth noting that Figure 5 presents evidence for the presence of the $\sim 25$-27-day temperature response to the solar rotation forcing that amplifies near altitudes of $\sim 40-45 \mathrm{~km}$ in the tropical stratosphere. The responses of the stratospheric ozone and temperature to variations in solar UV irradiance on the timescale of the solar rotation (27-day) have been studied since 1979 when space data became available (Hood, 2004). In this review the author reported that the sensitivity of ozone response to solar UV changes has been estimated to be highest during solar cycle maxima, reaching $0.5 \%$ in the upper stratosphere tropical regions 
while the temperature has maximum amplitude at about $0.06 \%(\sim 0.16 \mathrm{~K})$ per $1 \%$ change in the solar $205 \mathrm{~nm}$ flux near $1 \mathrm{hPa}$ level. Recently Ruzmaikin et al. (2007) have used new data obtained by the MLS onboard of Aura spacecraft to investigate variations in stratospheric ozone and temperature concurrent with the 27-day variations of solar UV irradiance, measured simultaneously by the Solar Radiation and Climate Experiment (SORCE) during the declining phase of solar cycle 23 (August 8, 2004-May 1, 2006). By applying of Empirical Mode Decomposition the authors determined the latitude and altitude distributions of the 27day modes for the ozone and temperature and found that these modes are enhanced in the tropical stratosphere (for temperature particularly at high tropical stratosphere) and in high latitudes. The presented here results revealed that the 27-day modes for temperature are seen at deep solar minimum as well.

\section{Regression model describing the stratospheric temperature and F10.7 influence on TEC variability}

The above obtained cross-correlation results provide an opportunity for creating a linear regression TEC model where the impact of both winter benchmark temperature variations and the day-to-day variability of F10.7 on the main TEC components, i.e. ZM and DW1, can be included. This simple regression model, based on the cross correlation coefficients and the respective standard deviations, will be used to quantify the contribution of stratospheric temperature and F10.7 to the variability of TEC. The model describes the dependence of ZM TEC and DW1 TEC, noted as $T E C_{Z M}$ and $T E C_{D W}$ respectively, on the modip latitude and the day by the regression equations:

$$
\begin{aligned}
& T E C_{Z M}(\text { mlat }, \text { day })=\alpha_{Z M T e m p}(\text { mlat }) T_{60}\left(\text { day }-t_{Z M T}\right)+\alpha_{Z M S o l}(\text { mlat }) F 107\left(\text { day }-t_{Z M F}\right)+\alpha_{Z M 00} \\
& T E C_{D W}(\text { mlat }, \text { day })=\alpha_{D W T e m p}(\text { mlat }) T_{60}\left(\text { day }-t_{D W T}\right)+\alpha_{D W S o l}(\text { mlat }) F 107\left(\text { day }-t_{D W F}\right)+\alpha_{D W 00}
\end{aligned}
$$

where $\alpha_{Z M T e m p}\left(\alpha_{D W T e m p}\right)$ and $\alpha_{Z M S o l}\left(\alpha_{D W S o l}\right)$ are regression coefficients describing the dependence of $T E C_{Z M}\left(T E C_{D W}\right)$ on winter benchmark temperature and solar variability respectively while $t_{Z M T}\left(t_{D W T}\right)$ and $t_{Z M F}\left(t_{Z M F}\right)$ are their time lags (in days). The last free members of the regressions $\alpha_{Z M 00}$ and $\alpha_{D W 00}$ are very small because we work with filtered data (the seasonal variation is removed in advance).

The regression coefficients and the respective time lags are defined by the least squares best fit approach. The obtained time lags in days as a function of the modip latitude (from $-80^{\circ}$ to $+80^{\circ}$ at each $5^{\circ}$ ) are presented in Table 1. Figure 6a shows the modip latitude dependence of the regression coefficients which describe $T E C_{Z M}$ (left plot) and $T E C_{D W}$ (right plot) variability due to stratospheric temperature and F10.7; the respective lines are clarified in the legend. The main features are evident right away: (i) the effects of the temperature and F10.7 on the TEC are the opposite: with increasing the temperature (F10.7) the TEC decreases (increases), and (ii) the shapes of both regression coefficients indicate that this model is valid mainly for the tropical region ( \pm 30 modip) where the equatorial anomaly is located and where the SSW response found by Pancheva and Mukhtarov (2011b) was the largest. Figure 6b presents the modip latitude dependence of the model RMSE (in TECU) calculated for $T E C_{Z M}$ and $T E C_{D W}$ (the respective lines are clarified in the legend). Certainly the largest errors are observed at tropical region reaching values of $\sim 1.8$ TECU and $\sim 1.3$ TECU respectively for $T E C_{Z M}$ and $T E C_{D W}$.

In order to compare the regression model with the TEC data variability and also to assess the relative contribution of the temperature and F10.7 to the TEC variability we calculate the STD 
of all above mentioned components. The results are presented in Figure 7 where the upper plot is for $T E C_{Z M}$ while the bottom plot is for $T E C_{D W}$. The different STDs are presented by different lines specified in the legend. The main features of the different STDs reveal that: (i) the presented linear regression model describes almost half of the real variability of the global TEC and (ii) the stratospheric temperature (i.e. that is a part of forcing from below) contribution is almost half of that from the F10.7 (i.e. external forcing related to the photoionization).

In order to understand better the above conclusions we remind that the regression model includes only day-to-day variability of F10.7 and the temperature variability (i.e. partly wind also). It is worth noting that the forcing from below by tides, GWs and PWs is not considered. Having in mind also that the geomagnetic activity is not included in the model then it is understandable why the model can describe only half of the real TEC variability. The contribution of the stratospheric temperature to the TEC variability is only half of that related to F10.7 but is not negligible and has to be included in modelling the global TEC.

Next we will demonstrate how the model works in considering the concrete Northern winters that belong to the period of time 2005-2010. The first example is the winter 2008/2009 when the famous major SSW event occurred. Figure 8a presents the residual (removed 31-day running mean) winter benchmark temperature data and residual F10.7 data (right plot) for the winter 2008/2009 (only from day numbers 40 to 140 are considered) while Figure 8 b shows the comparison between the variability of the two components, ZM TEC (upper row of plots) and DW1 TEC (bottom row of plots) calculated from the CODE TEC data (left column of plots) and the regression model. In order to facilitate the comparison the both scales (in TECU) are the same. The largest temperature peak near day number 115 (23 January) is related to the major SSW and according to the regression model it has to lead to a decrease of both ZM TEC and DW1 TEC. There is another, significantly smaller temperature peak, around day number 70 that also has to affect both TEC components negatively. The decrease of both TEC components to the largest temperature peak is well evident in both data and model having very similar magnitudes, about -2.4 TECU for ZM AND -2.7 TECU for DW1. The response to the weaker temperature peak can be distinguished in the model and partly in the ZM TEC data but in general the TEC decrease is small. This is due to the fact that there is an enhancement in F10.7 that leads to an increase of the TEC components. Although the solar activity is very low during the winter $2008 / 2009$ the residual F10.7 shows well visible $\sim 27$ day oscillations. All F10.7 maxima have to affect positively the two TEC components and this is seen in both data and model. The largest increase of both the model and data ZM and DW1components can be seen around day numbers 100-105. We note that this largest TEC increase is forced by two concurrently acting forcing processes: a negative temperature perturbation centred near day numbers 102-103 and a positive F10.7 disturbance maximizing around day 105; both processes lead to an increase of the TEC components.

Figure 9 is the same as Figure 8 but is for the Northern winter 2005/2006. As this winter belongs to moderate solar activity the magnitudes of the F10.7 variations are significantly larger than the winter 2008/2009 and the positive to them TEC response is stronger. We note that in this case the scales of the data and model are different; this is done to make the model results more clear. A careful inspection of all temperature (F10.7) peaks, seen in Figure 9a, shows that all of them have negative (positive) response to both TEC components in the model. Even the overlapping temperature and F10.7 peaks around days 60-70 that produce different responses can be distinguished in the model as a sequence of a negative response followed by a positive one. The CODE TEC data however this is well seen mainly in DW1 component. Both model and data have clear negative response to the largest temperature peak 
around day 105 but the magnitudes are different; for the model they are 2-2.5 TECU while for the data are 4 4.5-4.7 TECU.

The above considered two examples show that the presented regression model is able to capture well the negative TEC response caused by the temperature peaks in the high-latitude stratosphere mainly when the concurrent F10.7 peaks are weak.

\section{Discussion and summary}

This paper presents a simple linear regression model that enables to quantify the contribution of high-latitude stratospheric temperature and solar radiation (describes by its proxy F10.7) to the variability of the low-latitude TEC during winter. The model is based on the thorough cross-correlation analysis performed on the Aura MLS temperature measurements and the global CODE TEC data for the period of time 2005-2010. The cross-correlation analysis between the temperatures at all latitudes $\left( \pm 80^{\circ}\right)$ and altitudes (from $\sim 10 \mathrm{~km}$ to $\sim 90 \mathrm{~km}$ ) revealed that the temperature at altitude of $\sim 40 \mathrm{~km}$ and latitude of $\sim 60^{\circ} \mathrm{N}$ describes the most typical winter conditions and for the purpose of this study was called a winter benchmark temperature. The cross-correlation analysis between the temperature and TEC data showed that the largest negative correlation of the low-latitude TEC is found namely with the benchmark temperature. It is worth reminding again that the cross-correlation analysis was performed on the residual temperature and TEC data where their seasonal trends were removed in advance.

The cross-correlations between different temperatures as well as between the temperatures and the TEC data clearly showed the presence of extra-long planetary waves with periods of 20-25 days are present in both the middle atmosphere and the ionosphere. Therefore, these waves can be considered as an effective dynamic coupling agent in the atmosphereionosphere system. It is known that these waves are not normal modes and. they are not generated in the troposphere. For the first time Ebel et al. (1981) by using cross-spectral analysis investigated the effects of the solar variability with a period of 27 days, on the geopotential height and temperature fields in the stratosphere. The interpretation of their statistical results was based on a wave concept assuming that the correlations reflect modulation or perhaps generation of wave-like planetary-scale disturbances by radiation flux changes related to solar activity. They found three waves with periods, 25, 13.6, and 15.1 days that are coherent with solar activity fluctuations. Their detailed analysis on these waves led to the conclusion that these waves constitute three different structures caused by different response mechanisms of the stratosphere. They found also that the appearance of the maximum height and temperature perturbation is near $70^{\circ} \mathrm{N}$. The properties of the 25-day wave resemble those of vertically propagating internal waves. Later, Ebel et al. (1986) expanded this investigation by using various atmospheric parameters covering the height range 30-120 km. They found that solar forcing via the ozone layer plays a role in the generation of atmospheric perturbations at similar periods.

The global response to the solar activity, however, is essentially determined by the dynamical properties of the middle atmosphere, leading to strongest perturbations at middle and higher latitudes. Because of the nonlinearity of the perturbed atmosphere system, the response to the solar forcing could be in a rather broad band of periods (Dameris et al., 1986). Pancheva and Mitchell (2004) presented evidence for the presence of such vertically propagating waves in the field of zonal and meridional winds in the MLT region. The spatial structures and temporal variabilities of these waves have been shown later by 2D-analysis of the UK Met Office (UKMO) assimilated data (Pancheva et al., 2008b) and temperatures measured by the 
SABER instrument onboard the TIMED satellite (Pancheva et al., 2009). The latter results clearly revealed that these waves reach the lower thermosphere, i.e. dynamo region, where via the E-region dynamo can affect the ionospheric plasma (Pancheva and Mukhtarov, 2012c). Recently Hocke et al. (2013) by ground-based measurements of the ozone profiles above Switzerland have found long-period planetary oscillations, $\sim 20$ days, which amplify in winter. The authors suggested that they are possibly related to oscillations of the polar vortex edge in winter, i.e. to the long planetary waves in the dynamical regime. Therefore, the $\sim 20-25$-day waves found in this study could be generated by solar forcing.

The contribution of both the model and its two components (temperature and F10.7) to the variability of the TEC data was studied by calculating the STDs of all components (data, model, contributions of both temperature and F10.7). The comparison indicated that the regression model describes almost half of the real variability of the global TEC and that the contribution of the temperature (that is a part of forcing from below) is almost half of the solar variability (i.e. external forcing related to the photo-ionization). We underline again that the model considers only the impact of the stratospheric temperature on the ionosphere but does not include the effects of different atmospheric waves (tides, GWs and PWs) which are the main factor in the coupling process.

The key question in this study is why the found benchmark temperature (temperature at altitude of $\sim 40 \mathrm{~km}$ and latitude of $60^{\circ} \mathrm{N}$ ) revealed the strongest correlation with the lowlatitude TEC. It is known that the temperature changes are related with the neutral wind ones. Unfortunately the Aura MLS measurements do not have neutral wind ones but it is known that the neutral wind in the middle atmosphere is to a large extent close to the geostrophic one. It has been already mentioned that the Aura MLS instrument measures temperatures and geopotential heights. This means that the geostrophic wind can be calculated for all altitudes and for latitudes higher than $\sim 20^{\circ} \mathrm{N}$ (it is not valid near the equator). It is important to point out that the zonal mean circulation and the meridional temperature gradient define the background conditions which are important for the vertical propagation of some atmospheric waves. Due to this it would be interesting to see how the zonal mean circulation, determined by the geostrophic wind, depends on the temperature spatial and temporal distribution. Figure $10 \mathrm{a}$ presents the altitude structure of the cross-correlation coefficients with zero time lag between the temperatures at latitude of $60^{\circ} \mathrm{N}$ and the zonal geostrophic wind $U_{g}$ at latitude of $60^{\circ} \mathrm{N}$ (left plot) and $20^{\circ} \mathrm{N}$ (right plot). It is clearly evident that at latitude of $60^{\circ} \mathrm{N}$ the maximum negative correlation is observed between the temperature around $35-40 \mathrm{~km}$ and wind around $50-55 \mathrm{~km}$ height while at latitude of $20^{\circ} \mathrm{N}$ it is between the temperature at $\sim 40$ $\mathrm{km}$ and wind at $\sim 75 \mathrm{~km}$ as this negative correlation continues further up. The maximum correlation coefficients reach values of -0.5 and they are significant, i.e. above $95 \%$ confidence level. This result indicate that namely the temperature around altitude of $\sim 40 \mathrm{~km}$ and latitude of $60^{\circ} \mathrm{N}$, i.e. the benchmark temperature, has impact on the zonal mean circulation changes in winter not only at high latitudes but also at low latitudes as well.

In order to assess quantitatively the relationship between the temperature and zonal wind changes we calculate the linear regression (through the cross correlation coefficients and the respective standard deviations) between the benchmark temperature and the zonal geostrophic wind $U_{g}$ for all altitudes (from $\sim 10 \mathrm{~km}$ to $\sim 90 \mathrm{~km}$ ) and latitudes (from $20^{\circ} \mathrm{N}$ to $80^{\circ} \mathrm{N}$ ) and the result is shown in Figure 10b. The result clearly shows that with decreasing of latitude the negative impact of the benchmark temperature on the zonal wind goes up and at latitude of $20^{\circ} \mathrm{N}$ its maximum effect is at $\sim 80 \mathrm{~km}$ height. If the benchmark temperature increases with 1 $\mathrm{K}$ at altitude of $\sim 80 \mathrm{~km}$ the zonal wind will decrease with $2 \mathrm{~m} / \mathrm{sec}$ while at $\sim 65 \mathrm{~km}$ it will decrease with $5 \mathrm{~m} / \mathrm{sec}$. 
The above presented results pointed out the influence of the benchmark temperature on the mean zonal circulation in the middle atmosphere at high to low latitudes. It is known that the background conditions are important for the vertical propagation of some waves, particularly atmospheric tides. We mentioned in the Introduction that several groups reported observational evidence for enhanced semidiurnal variability of different ionospheric parameters during SSW events. By comparing the GAIA model results and satellite observations Jin et al. (2012) demonstrated that the ionospheric response to the major SSW in January 2009 is forced predominantly by the strongly amplified migrating semidiurnal tide (SW2) in the MLT region that affects the ionosphere via the modulated vertical plasma drift. The author stated that the amplification of the SW2 could be caused by two mechanisms: (i) redistribution of stratospheric ozone by meridional circulation and chemical processes connected with temperature changes, so the source of the SW2 changes, and (ii) SW2 propagation is changed due to the variations of the zonal background wind and meridional temperature gradient. The authors studied in detail the second mechanism and found that the changed background conditions act as an additional SW2 tidal source, especially the $(2,2)$ mode.

The obtained relationship between the benchmark temperature and zonal mean circulations (Figure 10) shows that the temperature increase will lead to a decrease of the eastward winter circulation which in turn will amplify the SW2 in the MLT region. It is important to note that the MLT SW2 tide has two important effects on the thermosphere and ionosphere: (i) due to dissipation of the enhanced SW2 tide during the SSW events a fountain-like meridional circulation is generated in the lower thermosphere (Liu et al., 2014), and (ii) SW2 itself causes the prominent semidiurnal variation of the ionosphere (Pancheva and Mukhtarov, 2012a). Recently Yamazaki and Richmond (2013) and Jones et al. (2014) have investigated the impact of the vertically propagating tides on the ionosphere-thermosphere system. They found that the main migrating tides influence the ionosphere by both vertical plasma drift modulation and changes in the neutral composition characterized by a reduction in the mass mixing ratio of atomic oxygen $\mathrm{O}_{1}$. Numerical simulation indicated that the mean meridional circulation induced by dissipating tides in the lower thermosphere is mainly responsible for the $\mathrm{O}_{1}$ reduction (Yamazaki and Richmond, 2013). Jones et al. (2014) reported that at low latitudes up to $13 \%$ decrease $\left(16 \%\right.$ increase) in mean $\mathrm{O}\left(\mathrm{O}_{2}\right)$ number density is produced in the presence of upward propagating tides. The change in $\mathrm{O}\left(\mathrm{O}_{2}\right)$ extents well into the F region ionosphere, where a maximum difference of $-10 \%(30 \%)$ is achieved. The decrease of $\mathrm{O}$ and increase of $\mathrm{O}_{2}$ lead to a $\sim 25 \%$ decrease in the mean electron density at $\mathrm{F}$ region altitudes. The decrease of the electron density in the ionosphere $\mathrm{F}$ region arises from a decrease in the production and an increase in the loss.

The above recently obtained results from numerical simulations indicated that the neutral composition changes generated by the enhanced SW2 could explain the observed decrease of the low latitude TEC, presented in this study, and also the results reported by Pancheva and Mukhtarov (2011). Bessarab et al. (2012) simulation results showed that by specifying the high-latitude perturbations in neutral temperature and density at the lower boundary of the thermosphere during SSW event, one can reproduce the decrease in $\mathrm{n}(\mathrm{O}) / \mathrm{n}(\mathrm{N} 2)$ ratio around the globe, which is one of the main reason for the negative disturbances in electron density during SSW 2009 event.

In conclusion we underline that nevertheless that the contribution of the stratospheric temperature to the TEC variability is only half of that related to F10.7, it is still not negligible and has to be included in modelling the global TEC. 
Acknowledgement: We are grateful to the CODE TEC team for the access to the TEC data provided from the CODE FTP directory: ftp://ftp.unibe.ch/aiub/CODE/ and to the Aura MLS team for the access to the data on: http://disc.sci.gsfc.nasa.gov/Aura/dataholdings/MLS/index.shtml. This work was supported by the European Office of Aerospace Research and Development (EOARD), Air Force Office of Scientific Research, Air Force Material Command, USAF, under grant number FA8655-12-1-2057 to D. Pancheva.

\section{REFERENCES}

Andrews, D.G., Holton, J.R., Leovy, C.B., 1987. Middle Atmosphere Dynamics. International Geophysics Series, 40, Academic Press, San Diego.

Baldwin, M.P., Dunkerton, T.J., 2001. Stratospheric harbingers of anomalous weather regimes. Science, 294, 581-584.

Bessarab, F.S., Korenkov, Yu.N., Klimenko, M.V., Klimenko, V.V., Karpov, I.V., Ratovsky, K.G., Chernigovskaya, M.A., 2012. Modeling the effect of sudden stratospheric warming within the thermosphere-ionosphere system. J. Atmos. Sol.-Terr. Phys. 90-91, 77-85.

Blanc, M., Richmond, A., 1980. The ionospheric disturbance dynamo. J. Geophys. Res., 85, A4, 1669-1686.

Charlton, A.J., Polvani, L.M., 2007. A new look at stratospheric sudden warmings: Part I: Climatology and modeling benchmarks. J. Climate, 20, 449-469, doi:10.1175/JCLI3996.1.

Chang, L.C., Lin, C.-H., Liu, J.-Y., Balan, N., Yue, J., Lin, J.-T., 2013. Seasonal and local time variation of ionospheric migrating tides in 2007-2011 FORMOSAT-3/COSMIC and TIE-GCM total electron content. J. Geophys. Res.- Space Physics, 118, doi:10.1002/jgra.50268.

Chau, J. L., Fejer, B.G., Goncharenko, L.P., 2009. Quiet variability of equatorial ExB drifts during a sudden stratospheric warming event. Geophys. Res. Lett., 36, L05101, doi:10.1029/2008GL036785.

Conde, M. G., Nicolls, M.J., 2010. Thermospheric temperatures above Poker Flat, Alaska, during the stratospheric warming event of January and February 2009. J. Geophys. Res., 115, D00N05, doi:10.1029/2010JD014280.

Dameris, M., Ebel, A., Jakobs, H. J., 1986. Three-dimensional simulation of quasi-periodic perturbations attributed to solar activity effects in the middle atmosphere, Ann. Geophys., 4, 287- 296.

Ebel, A., Schwister, B., Labitzke, K., 1981. Planetary waves and solar activity in the stratosphere between 50 and 10 mbar, J. Geophys. Res., 86(C10), 9729- 9738.

Ebel, A., Dameris, M., Hass, H., Manson, A. H., Meek, C. E., Petzoldt, K., 1986. Vertical change of the response to solar activity oscillations with periods around 13 and 27 days in the middle atmosphere, Ann. Geophys., 4, 271-280.

Forbes, J.M., Zhang, X., Palo, S., Russell, J., Mertens, C. J., Mlynczak, M., 2008. Tidal variability in the ionospheric dynamo region, J. Geophys. Res., 113, A02310, doi:10.1029/2007JA012737. 
Funke, B., López-Puertas, M., Bermejo-Pantaleón, D., García-Comas, M., Stiller, G.P., von Clarmann, T., Kiefer, M., Linden, A., 2010. Evidence for dynamical coupling from the lower atmosphere to the thermosphere during a major stratospheric warming. Geophys. Res. Lett., 37, L13803, doi:10.1029/2010GL043619..

Goncharenko, L., Zhang, S., 2008. Ionospheric signatures of sudden stratospheric warming: Ion temperature at middle latitude. Geophys. Res. Lett., 35, L21103, doi:10.1029/ 2008 GL035684.

Goncharenko, L.P., Chau, J.L., Liu, H.-L., Coster, A.J., 2010a. Unexpected connections between the stratosphere and ionosphere. Geophys. Res. Lett., 37, L10101, doi:10.1029/ 2010GL043125.

Goncharenko, L., Coster, A., Chau, J., Valladares, C., 2010b. Impact of sudden stratospheric warmings on equatorial ionization anomaly. J. Geophys. Res., 115, A00G07, doi:10.1029/ 2010JA015400.

Hocke, K., Studer, S., Martius, O., Scheiben1, D., Kämpfer, N., 2013. A 20-day period standing oscillation in the northern winter stratosphere, Ann. Geophys., 31, 755-764, doi:10.5194/angeo-31-755-2013.

Hood, L. L., 2004. Effects of solar variability on the stratosphere, in Solar Variability and its Effects on Climate, Geophys. Mongr. Ser., 141, 283-303, AGU, Washington, D. C.

Iida, C., Hirooka, T., Eguchi, N., 2014. Circulation changes in the stratosphere and mesosphere during the stratospheric sudden warming event in January 2009. J. Geophys. Res. -Atmospheres, 119, doi:10.1002/2013JD021252.

Jin, H., Miyoshi, Y., Pancheva, D., Mukhtarov, P., Fujiwara, H., Shinagawa, H., 2012. Response of migrating tides to the stratospheric sudden warming in 2009 and their effects on the ionosphere studied by a whole atmosphere-ionosphere model GAIA with COSMIC and TIMED/SABER observations. J. Geophys. Res., 117, A10323, doi:10.1029/2012JA017650

Jones, M. Jr., Forbes, J.M., Hagan, M.E., Maute, A., 2014. Impact of vertically propagating tides on the mean state of the ionosphere-thermosphere system. J. Geophys. Res., 119, 2197-2213, doi:10.1002/2013JA019744.

Korenkov, Y.N., Klimenko, V.V., Klimenko, M.V., et al., 2012. The global thermospheric and ionospheric response to the 2008 minor sudden stratospheric warming event. J. Geophys. Res., 117, A10309, doi:10.1029/2012JA018018.

Krüger, K., Naujokat, B., Labitzke, K., 2005. The unusual midwinter warming in the Southern Hemisphere stratosphere 2002: A comparison to Northern Hemisphere phenomena. J. Atmos. Sci., 62, 603-613.

Kurihara, J., Ogawa, Y., Oyama, S., Nozawa, S., Tsutsumi, M., Hall, C.M., Tomikawa, Y., Fujii, R., 2010. Links between a stratospheric sudden warming and thermal structures and dynamics in the high-latitude mesosphere, lower thermosphere, and ionosphere. Geophys. Res. Lett., 37, L13806, doi:10.1029/2010GL043643.

Laskar, F.I., Pallamraju, D., 2014. Does sudden stratospheric warming induce meridional circulation in the mesosphere thermosphere system?. J. Geophys. Res., 119, 10133-10143, doi: 10.1002/2014JA020086.

Lin, J.T., Lin, C.H., Chang, L.C., Huang, H.H., Liu, J.Y., Chen, A.B., Chen, C.H., Liu, C.H., 2012. Observational evidence of ionospheric migrating tide modification during the 2009 
stratospheric sudden warming. Geophys. Res. Lett., 39, L02101, doi:10.1029/2011GL050248.

Liu, H.-L., Roble, R.G., 2002. A study of a self-generated stratospheric sudden warming and its mesospheric-lower thermospheric impacts using the coupled TIME-GCM/CCM3. J. Geophys. Res., 107, D23, 4695, doi:10.1029/2001JD001533.

Liu, H.-L., Wang, W., Richmond, A.D., Roble, R.G., 2010. Ionospheric variability due to planetary waves and tides for solar minimum conditions. J. Geophys. Res., 115, A00G01, doi:10.1029/2009JA015188.

Liu, H., Doornbos, E., Yamamoto, M., Tulasi Ram, S., 2011. Strong thermospheric cooling during the 2009 major stratosphere warming. Geophys. Res. Lett., 38, L12102, doi:10.1029/2011GL047898.

Liu, H., Jin, H., Miyoshi, Y., Fujiwara, H., Shinagawa, H., 2013. Upper atmosphere response to stratosphere sudden warming: Local time and height dependence simulated by GAIA model. Geophys. Res. Lett., 40, 635-640, doi:10.1002/grl.50146.

Liu, H., Miyoshi, Y., Miyahara, S., Jin, H., Fujiwara, H., Shinagawa, H., 2014. Thermal and dynamical changes of the zonal mean state of the thermosphere during the 2009 SSW: GAIA simulations. J. Geophys. Res. - Space Physics, 119, 6784-6791, doi:10.1002/2014JA020222.

Livesey, N., Filipiak, M., Froidevaux, L., et al., 2008. Validation of Aura Microwave Limb Sounder $\mathrm{O} 3$ and $\mathrm{CO}$ observations in the upper troposphere and lower stratosphere. J. Geophys. Res., 113, doi:10.1029/2007JD008805.

Matsuno, T., 1971. A dynamical model of the stratospheric sudden warming, J. Atmos. Sci., $28,1479-1494$.

McIntyre, M. E., 1982. How well do we understand the dynamics of stratospheric warmings? J. Met. Soc. Japan, 60, 37-65.

Mukhtarov, P., Pancheva, D., Andonov, B., Mitchell, N.J., Singer, W., Hocking, W., Manson, A., Meek, C., Murayama, Y., Merzlyakov, E., 2007. Large-scale thermodynamics of the stratosphere and mesosphere during the major stratospheric warming in 2003/2004. J. Atmos. Sol-Terr. Phys., 69, 2338-2354.

Mukhtarov, P., Pancheva, D., 2011. Global ionospheric response to nonmigrating DE3 and DE2 tides forced from below. J. Geophys. Res., 116, A05323, doi:10.1029/2010JA016099.

Mukhtarov, P., Andonov, B., Pancheva, D., 2013. Global empirical model of TEC response to geomagnetic activity. J. Geophys. Res. - Space Physics, 118, 6666-6685, doi:10.1002/ jgra.50576.

Oyama, K.-I., Jhou, J.T., Lin, J.T., Lin, C., Liu, H., Yumoto, K., 2014. Ionospheric response to 2009 sudden stratospheric warming in the Northern Hemisphere. J. Geophys. Res., 119, 10,260-10,275, DOI: 10.1002/2014JA020014.

Pancheva, D., Mitchell, N.J., 2004. Planetary waves and variability of the semidiurnal tide in the mesosphere and lower thermosphere over Esrange $\left(68^{\circ} \mathrm{N}, 21^{\circ} \mathrm{E}\right)$ during winter, $\mathrm{J}$. Geophys. Res., 109, A08307, doi:10.1029/2004JA010433.

Pancheva, D.V., Mukhtarov, P.J., Andonov, B.A., 2007. Zonally symmetric oscillations in the Northern hemisphere stratosphere during the winter of 2003/2004. Geophys. Res. Lett., 34, L04807, doi:10.1029/2006GL028666. 
Pancheva, D., Mukhtarov, P., Mitchell, N.J., Andonov, B., Merzlyakov, E., Singer, W., Murayama, Y., Kawamura, S., Xiong, J., Wan, W., Hocking, W., Fritts, D., Riggin, D., Meek, C., Manson, A., 2008a. Latitudinal Wave Coupling of the Stratosphere and Mesosphere during the Major Stratospheric Warming in 2003/2004. Ann. Geophys., 26, 467-483.

Pancheva, D., Mukhtarov, P., Mitchell, N.J., Merzlyakov, E.,. Smith, A.K, Andonov, B., Singer, W., Hocking, W., Meek, C., Manson, A., Murayama, Y., 2008b. Planetary Wave Coupling of the Stratosphere and Mesosphere during the Major Stratospheric Warming in 2003/2004, J. Geophys. Res. - Atmospheres, 113, D12105, doi:10.1029/2007JD009011.

Pancheva D., Mukhtarov, P., Andonov, B., Mitchell, N.J., Forbes, J., 2009. Planetary waves observed by TIMED/SABER in coupling the stratosphere-mesosphere-lower thermosphere during the winter of 2003/2004: Part 2, Altitude and latitude planetary wave structures, J. Atmos. Sol.-Terr. Phys., 71, No 1, 75-87.

Pancheva, D., Mukhtarov, P., 2011. Stratospheric warmings: The atmosphere-ionosphere coupling paradigm. J. Atmos. Sol-Terr. Phys., 73, 1697-1702, doi:10.1016/j.jastp.2011.03.066.

Pancheva, D., Mukhtarov, P., 2012a. Global response of the ionosphere to atmospheric tides forced from below: Recent progress based on satellite measurements. Space Sci. Rev., 168(1-4), 175-209, doi:10.1007/s11214-011-9837-1.

Pancheva, D., Mukhtarov, P., 2012b. Semidiurnal tidal response to the sudden stratospheric warming in January 2009 and its effect on the ionosphere. Comp. rend. Acad. bulg. Sci., 65, No 8, 1125-1134.

Pancheva, D., Mukhtarov, P., 2012c. Planetary wave coupling of the atmosphere-ionosphere system during the Northern winter of 2008/2009, Adv. Space Res., 50, 1189-1203.

Pancheva, D., Miyoshi, Y., Mukhtarov, P., Jin, H., Shinagawa, H., Fujiwara, H., 2012. Global response of the ionosphere to atmospheric tides forced from below: Comparison between COSMIC measurements and simulations by atmosphere-ionosphere coupled model GAIA. J. Geophys. Res., 117, A07319, doi:10.1029/2011JA017452.

Rawer, K., 1984. (Ed.), Encyclopedia of Physics, Geophysics III, Part VII. Springer-Verlag, 389-391.

Ruzmaikin, A., Santee, M. L., Schwartz, M. J., Froidevaux, L., Pickett, H., 2007. The 27-day variations in stratospheric ozone and temperature: New MLS data, Geophys. Res. Lett., 34, L02819, doi:10.1029/2006GL028419.

Shepherd, M.G., Wu, D.L., Fedulina, I.N., Gurubaran, S., Russell, J.M., Mlynczak, M.G., Shepherd, G., 2007. Stratospheric warming effects on the tropical mesospheric temperature field. J. Atmos. Solar-Terr. Phys., 69, 2309-2337.

Schaer, S., 1999. Mapping and Predicting the Earth's Ionosphere Using the Global Positioning System, Geod. Geophys. Arb. Schweiz., vol. 59, Inst. für Geod. und Photogramm., Zurich, Switzerland.

Schwartz, M.J., Lambert, A., Manney, G.L., et al., 2008. Validation of the Aura Microwave Limb Sounder temperature and geopotential height measurements. J. Geophys. Res., 113, D15S11, doi:10.1029/2007JD008783.

Yamazaki, Y., Richmond, A.D., 2013. A theory of ionospheric response to upwardpropagating tides: Electrodynamic effects and tidal mixing effects. J. Geophys. Res.Space Physics, 118, 5891-5905, doi:10.1002/jgra.50487. 


\section{FIGURE CAPTIONS}

Table 1 Time lags in days as a function of the modip latitude from $-80^{\circ}$ to $+80^{\circ}$ at each $5^{\circ}$.

Figure 1 (left column) Altitude structure of the cross-correlation functions between the temperature at latitude of $60^{\circ} \mathrm{N}$ and altitude of $\sim 40 \mathrm{~km}$ with the temperatures at the equator (upper plot), $60^{\circ} \mathrm{N}$ (middle plot) and $80^{\circ} \mathrm{N}$ (bottom plot); (right column) Latitude structure of the cross-correlation functions between the temperature at latitude of $60^{\circ} \mathrm{N}$ and altitude of $\sim 40$ $\mathrm{km}$ with the temperatures at altitudes of $\sim 82 \mathrm{~km}$ (upper plot), $\sim 40 \mathrm{~km}$ (middle plot) and $\sim 31$ $\mathrm{km}$ (bottom plot); the white line represents the zero cross-correlation coefficient.

Figure 2 (left column) Latitude structure of the cross-correlation functions between the ZM TEC and ZM temperature at: (i) latitude of $60^{\circ} \mathrm{N}$ and altitude of $\sim 40 \mathrm{~km}$ (upper plot); (ii) the equator and altitude of $\sim 40 \mathrm{~km}$ (middle plot) and (iii) the equator and altitude of $\sim 90 \mathrm{~km}$ (bottom plot); (right column) the same as the left column but the cross-correlation is with the DW1 TEC.

Figure 3 (left column) Altitude structure of the cross-correlation function between the ZM TEC at the equator and the ZM temperature at: (i) latitude of $60^{\circ} \mathrm{N}$ (upper plot); (ii) the equator (middle plot) and (iii) latitude of $80^{\circ} \mathrm{N}$ (bottom plot); (right column) the same as the left column but the cross-correlation is with the DW1 TEC at the equator.

Figure 4 (a) Daily values of F10.7 for the period of time 2005-2010; (b) Latitude structure of the cross-correlation functions of F10.7 with ZM TEC (upper plot) and DW1 TEC (bottom plot).

Figure 5 (a) Altitude structure of the cross-correlation functions of F10.7 with the ZM temperatures at the equator (left plot) and at latitude of $20^{\circ} \mathrm{N}$ (right plot); (b) Latitude structure of the cross-correlation functions of F10.7 with the ZM temperatures at $\mathrm{h} \sim 44 \mathrm{~km}$ (left plot) and h 40 km (right plot).

Figure 6 (a) Modip latitude dependence of the regression coefficients which describe ZM TEC (left plot) and DW1 TEC (right plot); (b) Modip latitude dependence of the model RMSE (in TECU) calculated for ZM TEC and DW1 REC.

Figure 7 Modip latitude dependence of the standard deviations of ZM TEC (upper plot) calculated from the CODE data, full model, solar part of the model and temperature part of the model; (bottom plot) the same as the upper plot but for the standard deviations of DW1 TEC.

Figure 8 (a) Residual temperature data (left plot) at $\mathrm{h} \sim 40 \mathrm{~km}$ and latitude of $60^{\circ} \mathrm{N}$ and residual F10.7 data (right plot) for the Northern winter 2008/2009; (b) Modip latitude structure of the ZM TEC (upper row of plots) and DW1 TEC (bottom row of plots) components calculated from the CODE TEC data (left column of plots) and the linear regression model (right column of plots).

Figure 9 (a) Residual temperature data (left plot) at $\mathrm{h} \sim 40 \mathrm{~km}$ and latitude of $60^{\circ} \mathrm{N}$ and residual F10.7 data (right plot) for the Northern winter 2005/2006; (b) Modip latitude structure of the ZM TEC (upper row of plots) and DW1 TEC (bottom row of plots) components calculated from the CODE TEC data (left column of plots) and the linear regression model (right column of plots).

Figure 10 (a) Altitude structure of the cross-correlation coefficients with zero time lag between the temperatures at latitude of $60^{\circ} \mathrm{N}$ and the zonal geostrophic winds $U_{g}$ at latitude of $60^{\circ} \mathrm{N}$ (left plot) and $20^{\circ} \mathrm{N}$ (right plot); (b) Linear regression between the temperature $T$ at 
latitude of $60^{\circ} \mathrm{N}$ and altitude of $40 \mathrm{~km}$ and the zonal geostrophic wind $U_{g}$ at considered latitudes and altitudes. Zero regression is marked by a thick white line.

Table 1

Time lags in days as a function of the modip latitude from $-80^{\circ}$ to $+80^{\circ}$ at each $5^{\circ}$

\begin{tabular}{|ccccc|ccccc|}
\hline $\begin{array}{c}\text { Modiplat } \\
\text { (degree })\end{array}$ & $t_{Z M F}$ & $t_{Z M T}$ & $t_{D W F}$ & $t_{D W T}$ & $\begin{array}{c}\text { Modiplat } \\
\text { (degree })\end{array}$ & $t_{Z M F}$ & $t_{Z M T}$ & $t_{D W F}$ & $t_{D W T}$ \\
\hline-80 & 0 & 0 & 4 & 0 & 5 & 1 & 0 & 2 & 1 \\
-75 & 1 & 0 & 1 & 0 & 10 & 1 & 0 & 1 & 0 \\
-70 & 1 & 0 & 1 & 0 & 15 & 1 & 0 & 1 & 0 \\
-65 & 1 & 0 & 2 & 2 & 20 & 1 & 0 & 1 & 0 \\
-60 & 1 & 0 & 2 & 0 & 25 & 1 & 0 & 1 & 0 \\
-55 & 1 & 0 & 2 & 0 & 30 & 1 & 0 & 1 & 0 \\
-50 & 1 & 0 & 2 & 0 & 35 & 1 & 0 & 1 & 0 \\
-45 & 1 & 0 & 2 & 0 & 40 & 1 & 0 & 2 & 0 \\
-40 & 1 & 0 & 1 & 0 & 45 & 1 & 0 & 2 & 0 \\
-35 & 1 & 0 & 1 & 0 & 50 & 1 & 0 & 2 & 0 \\
-30 & 1 & 0 & 1 & 0 & 55 & 1 & 0 & 1 & 1 \\
-25 & 1 & 0 & 1 & 0 & 60 & 1 & 0 & 1 & 2 \\
-20 & 1 & 0 & 1 & 0 & 65 & 1 & 0 & 1 & 2 \\
-15 & 1 & 0 & 1 & 0 & 70 & 1 & 0 & 0 & 2 \\
-10 & 1 & 0 & 2 & 0 & 75 & 1 & 0 & 0 & 3 \\
-5 & 1 & 0 & 2 & 1 & 80 & 1 & 0 & 0 & 3 \\
0 & 1 & 0 & 2 & 1 & & & & & \\
\hline
\end{tabular}



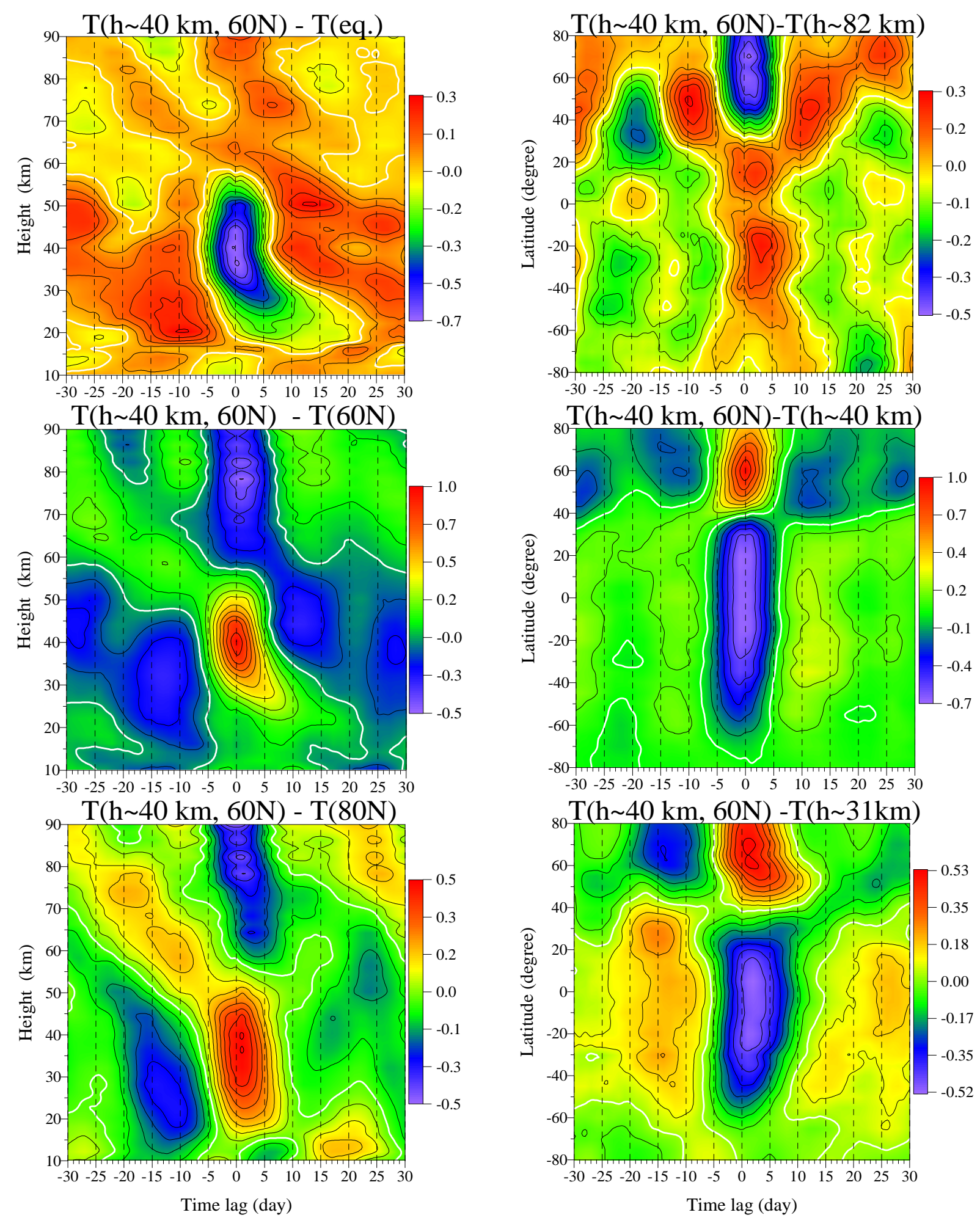

Figure 1 

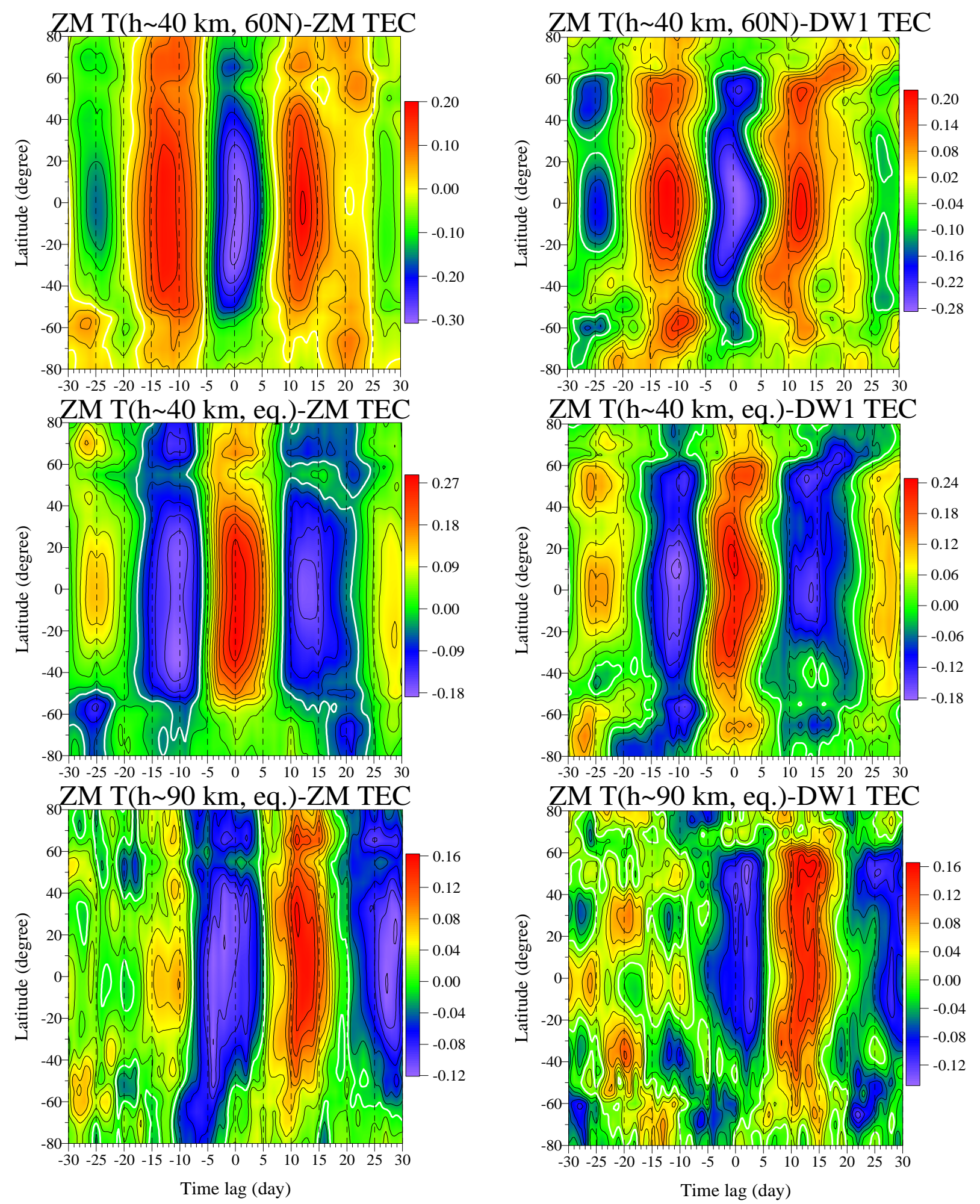

Figure 2 

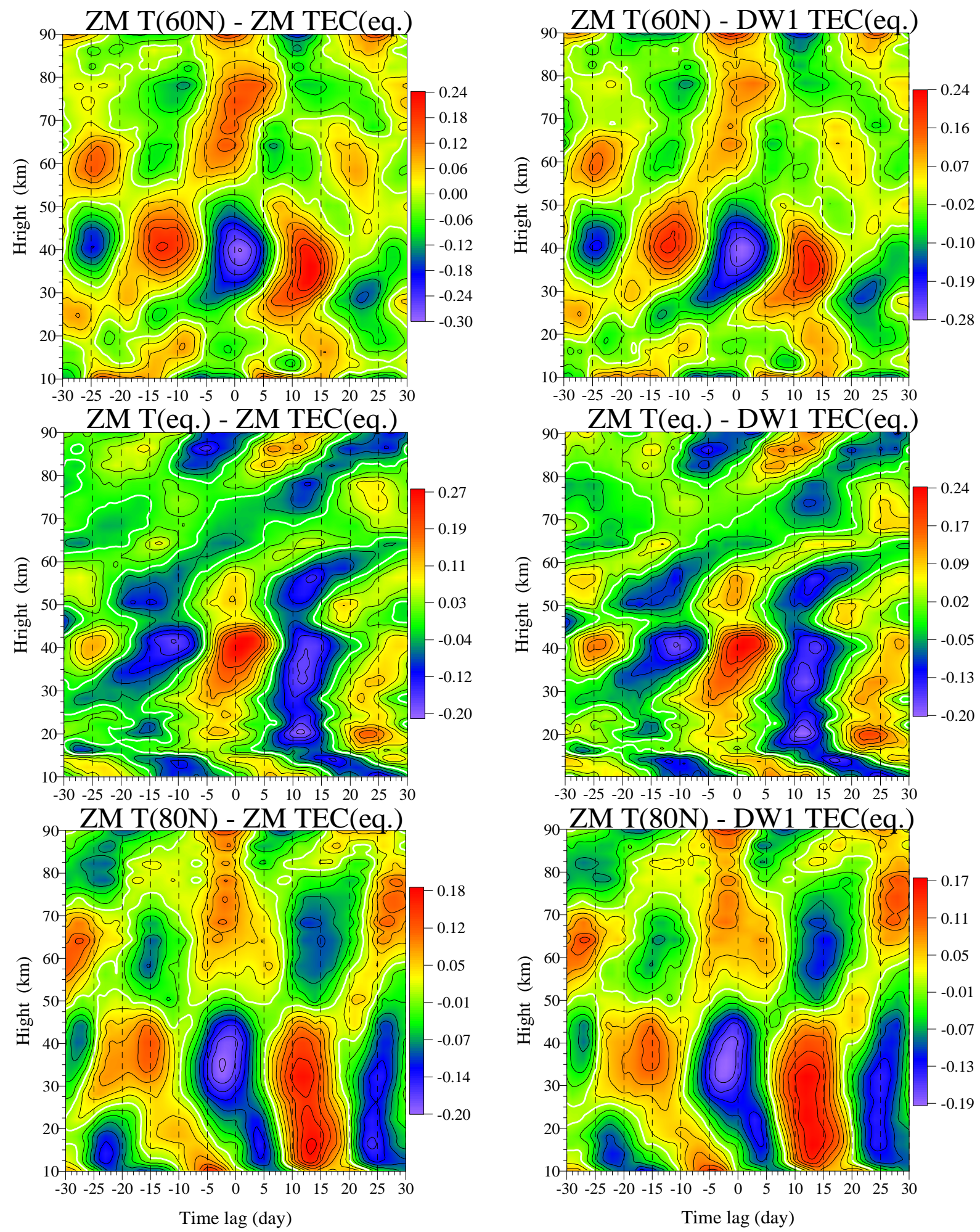

Figure 3 
(a)

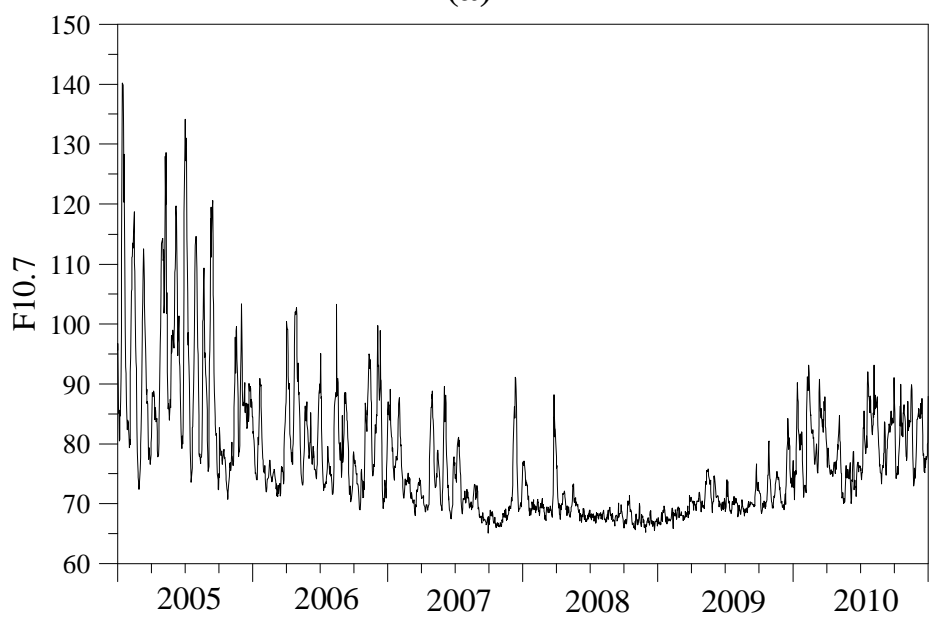

(b)
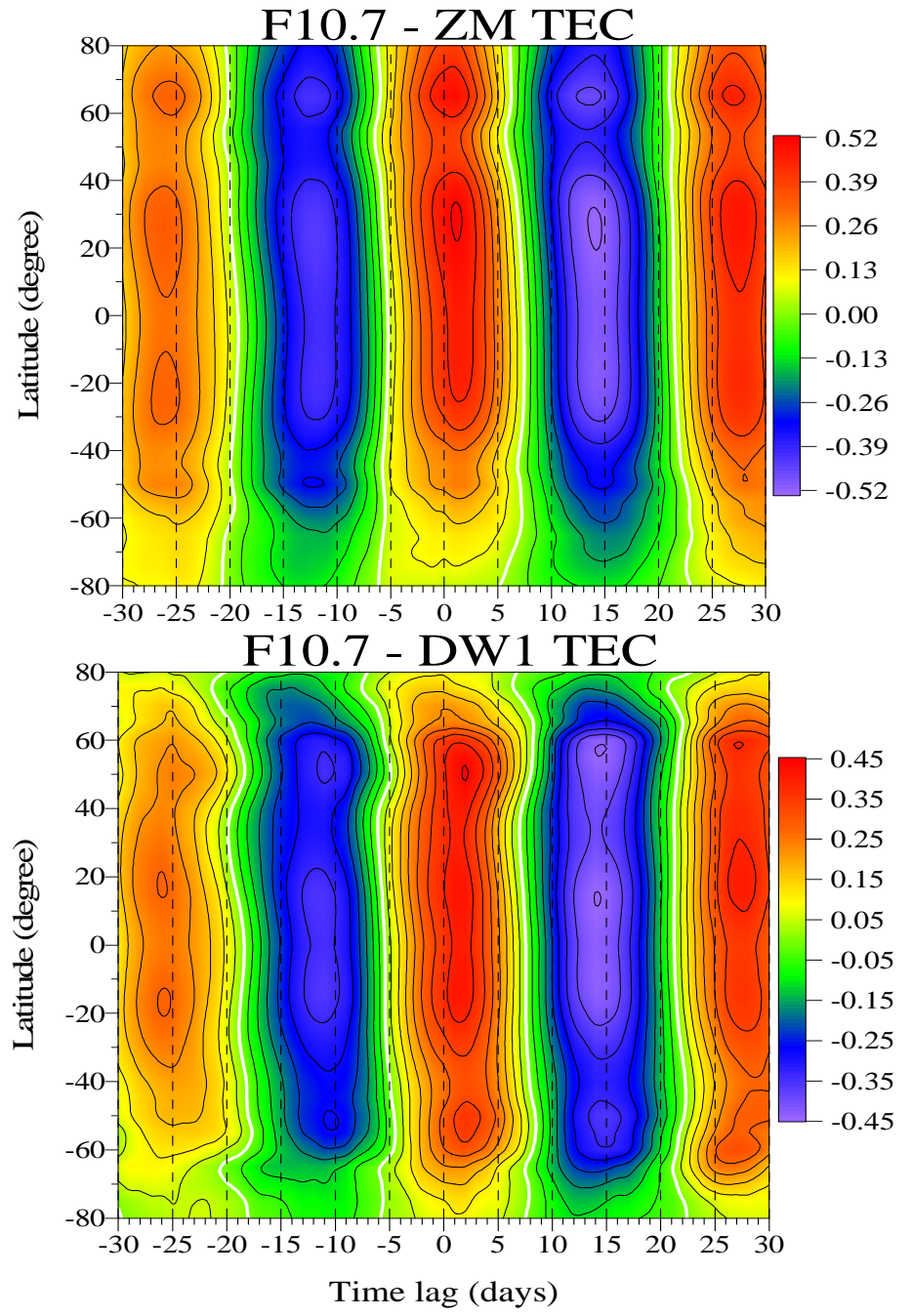

Figure 4 
(a)
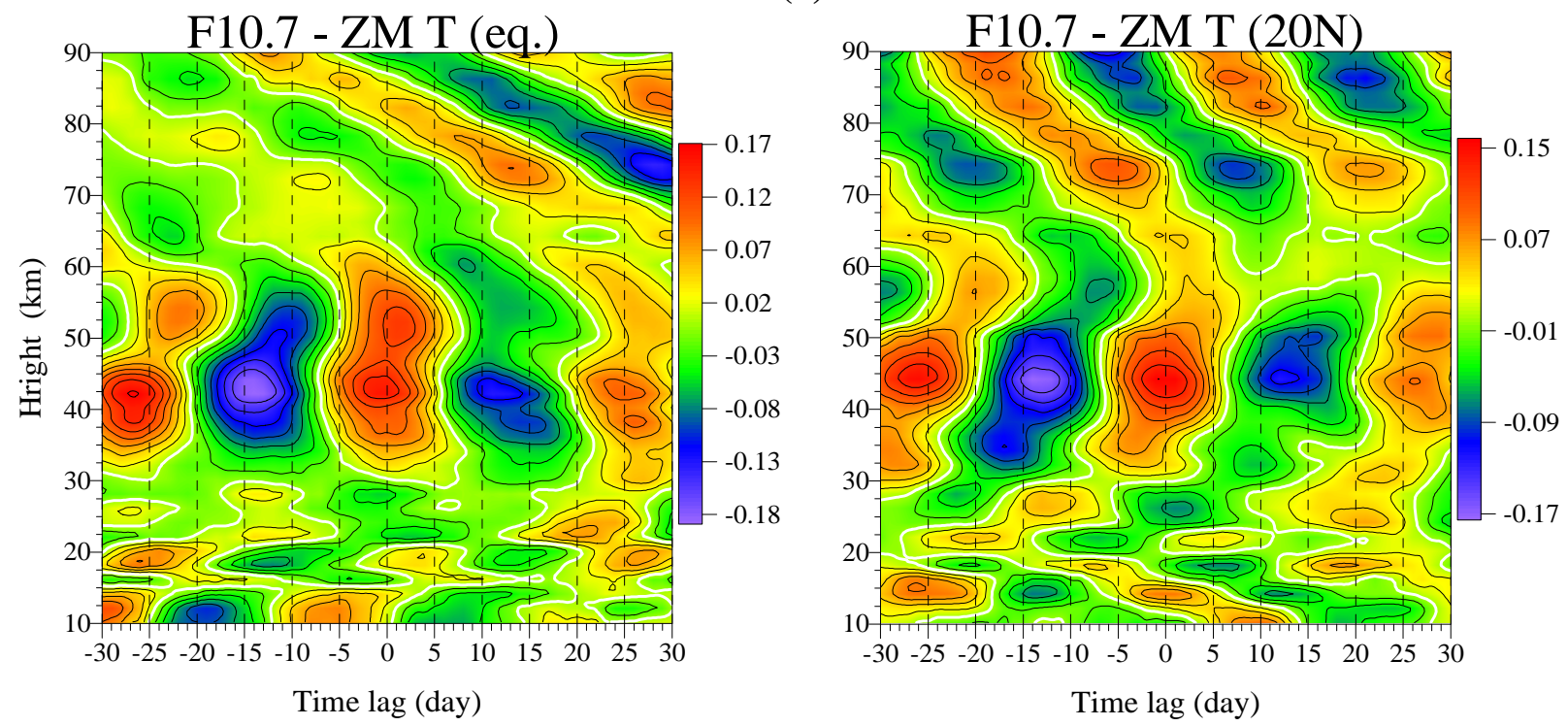

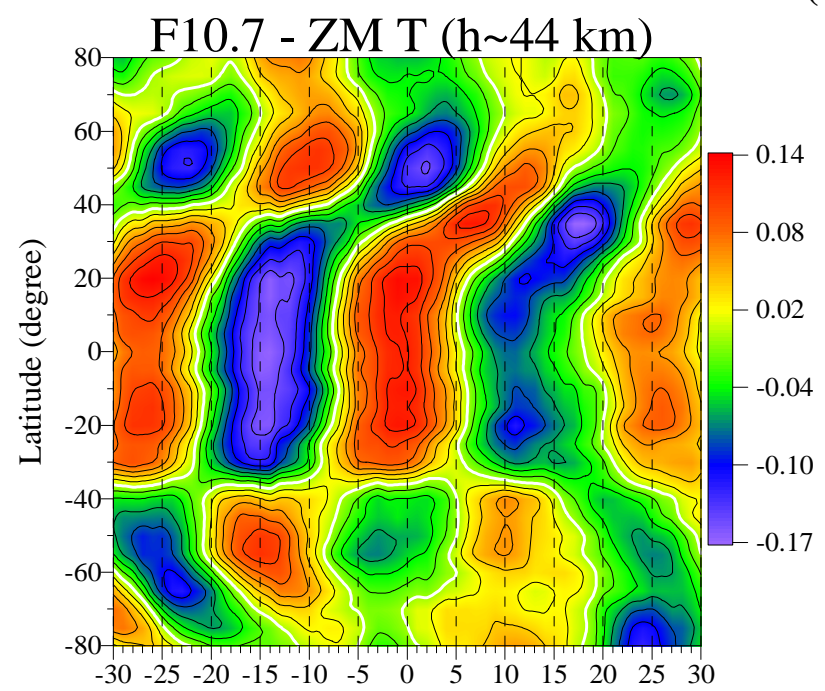

Time lag (day) (b)

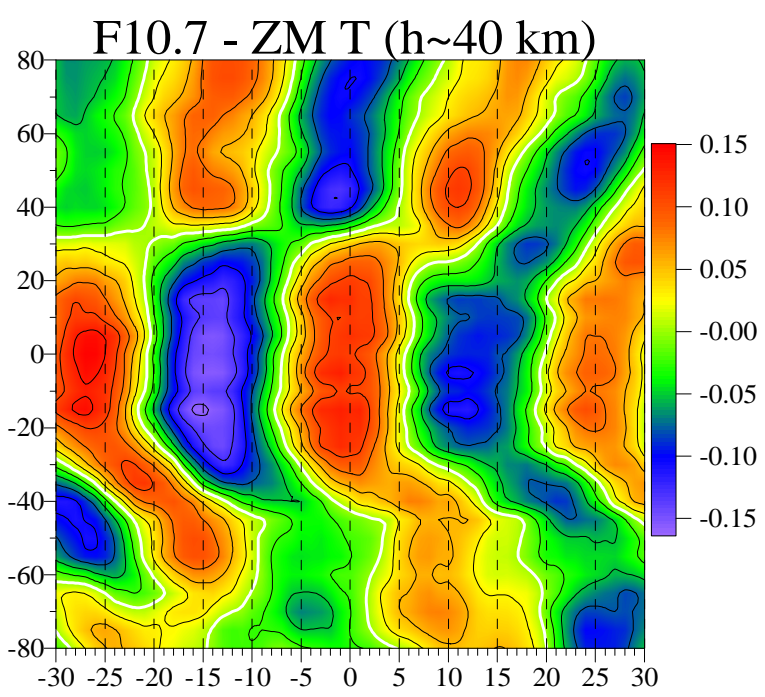

Time lag (day)

Figure 5 
(a)
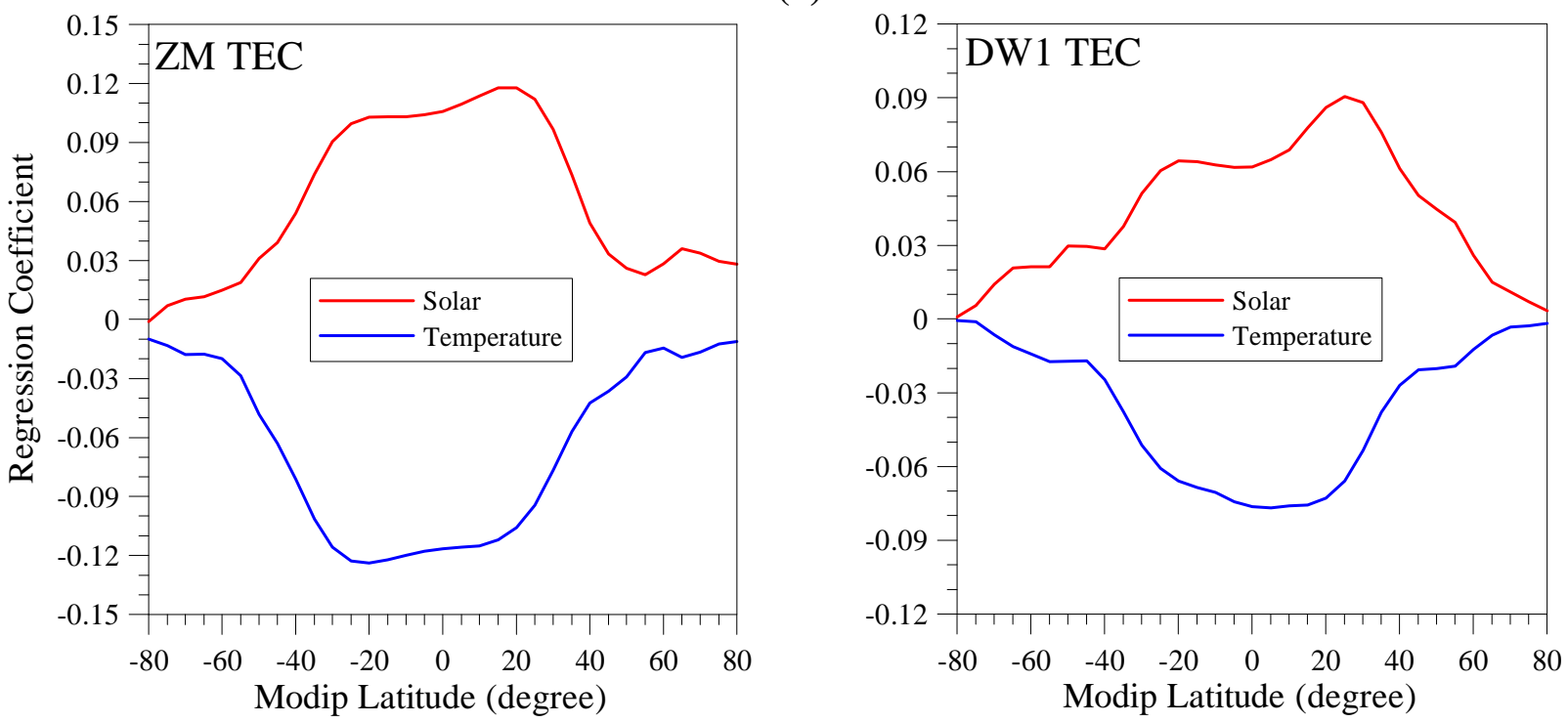

(b)

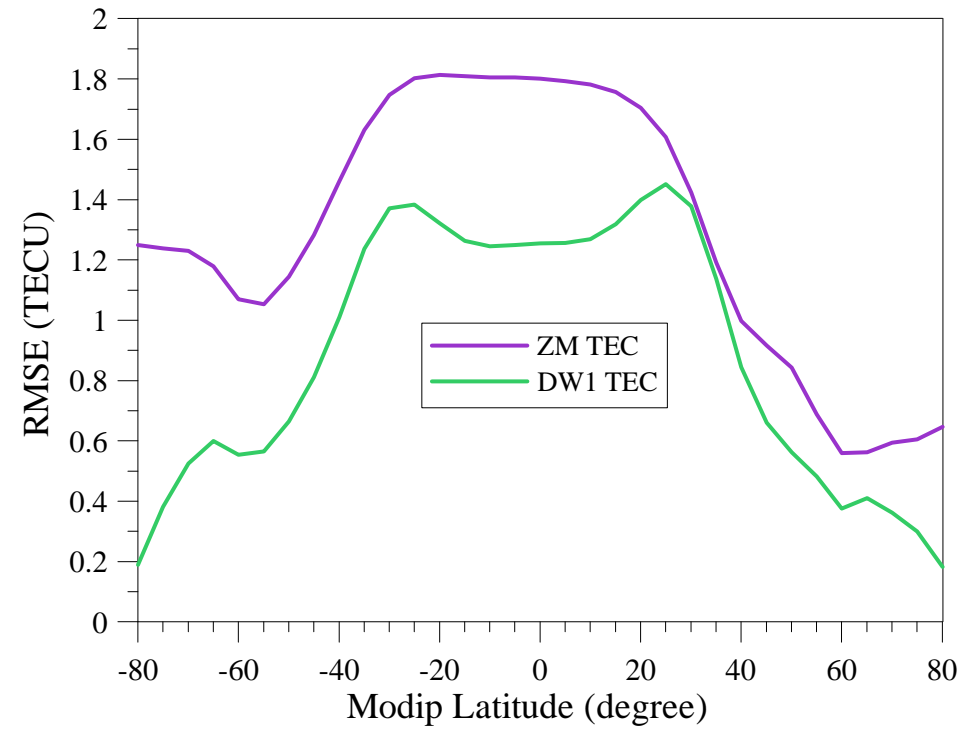

Figure 6 

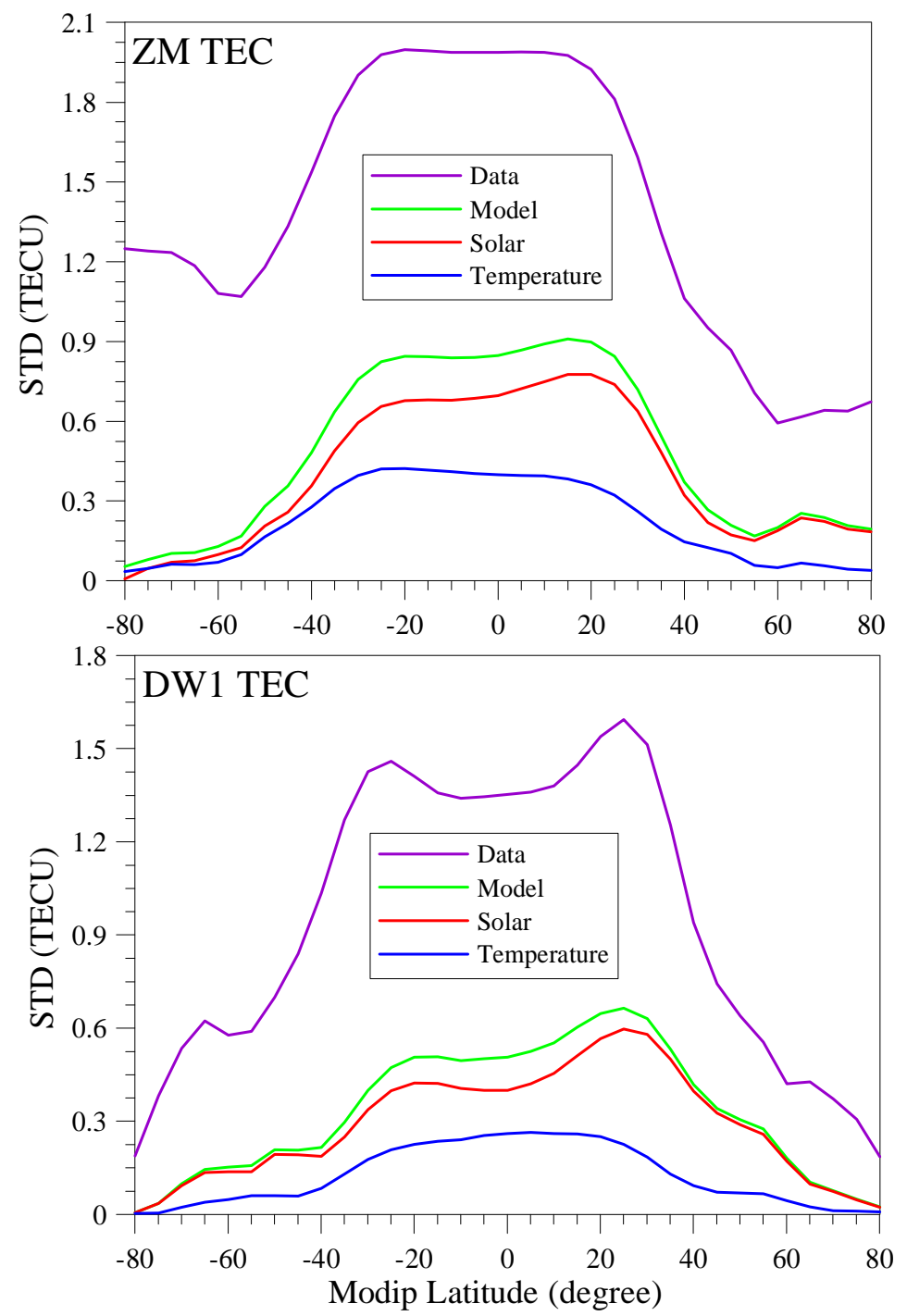

Figure 7 
(a)
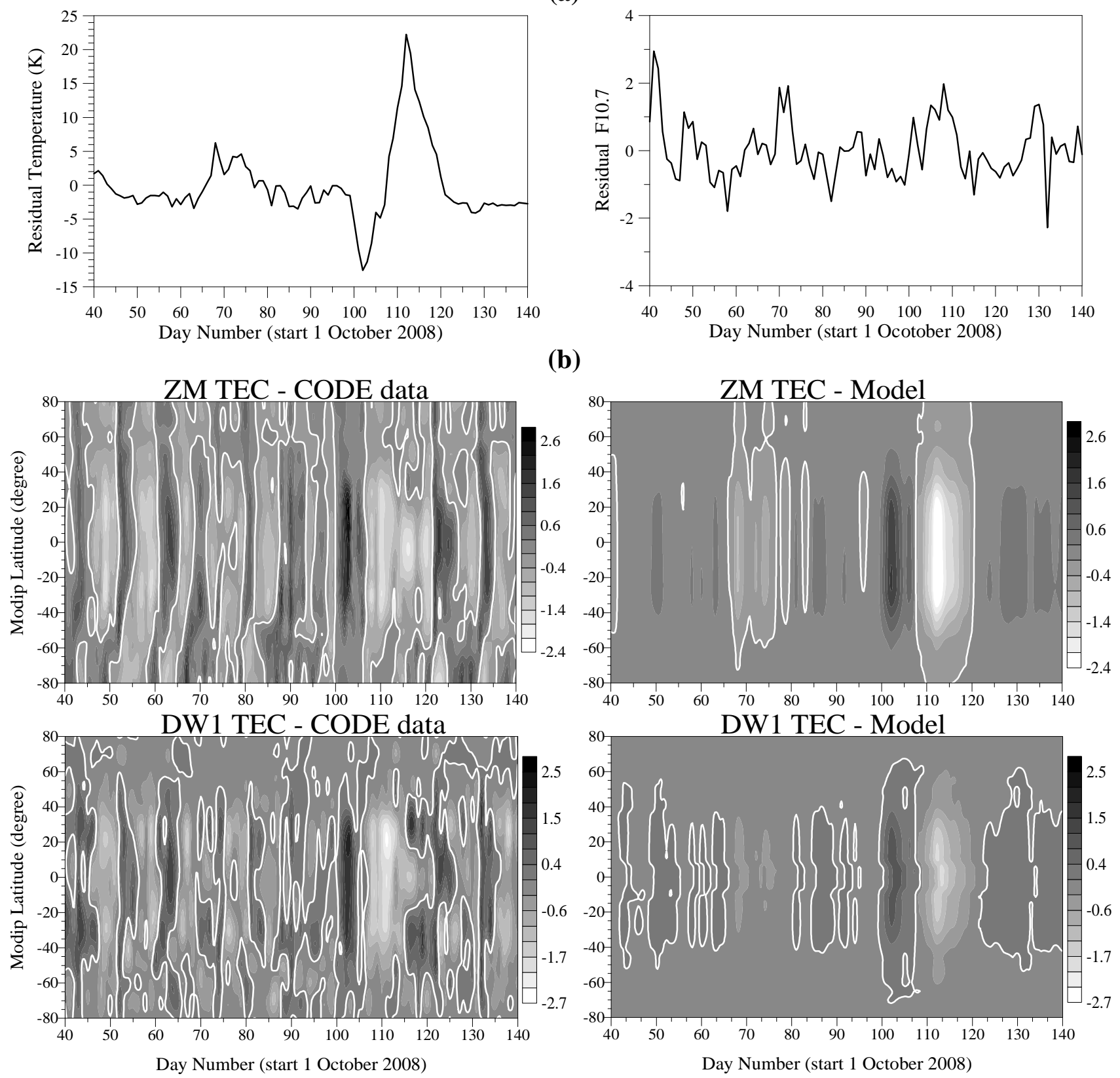

Figure 8 
(a)
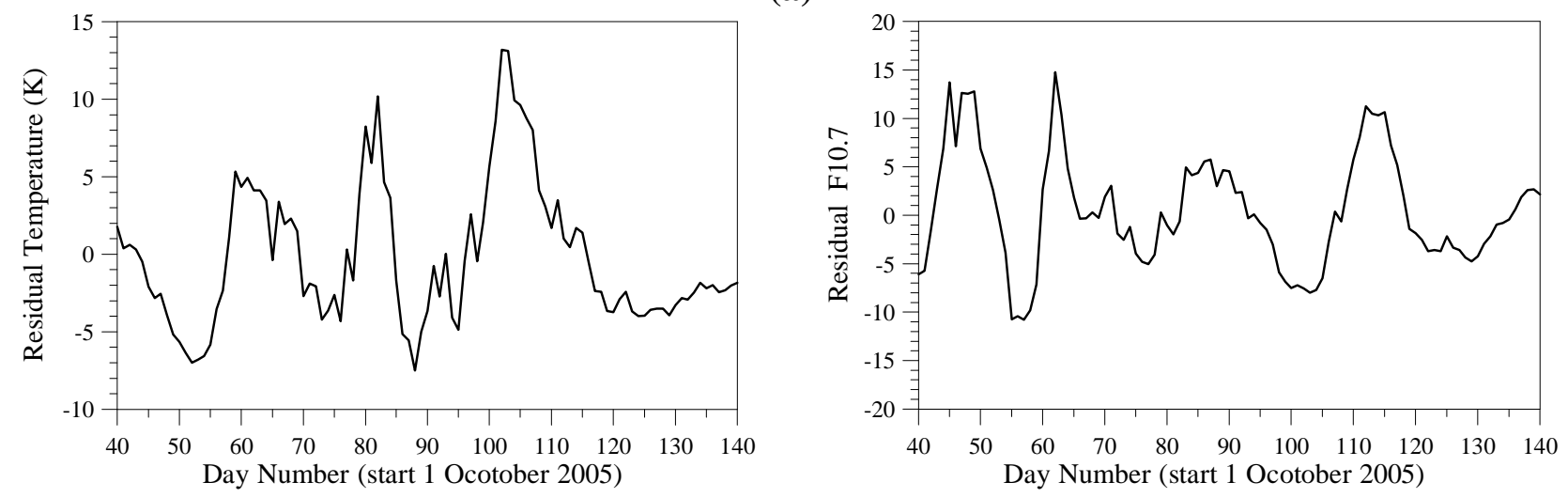

(b)
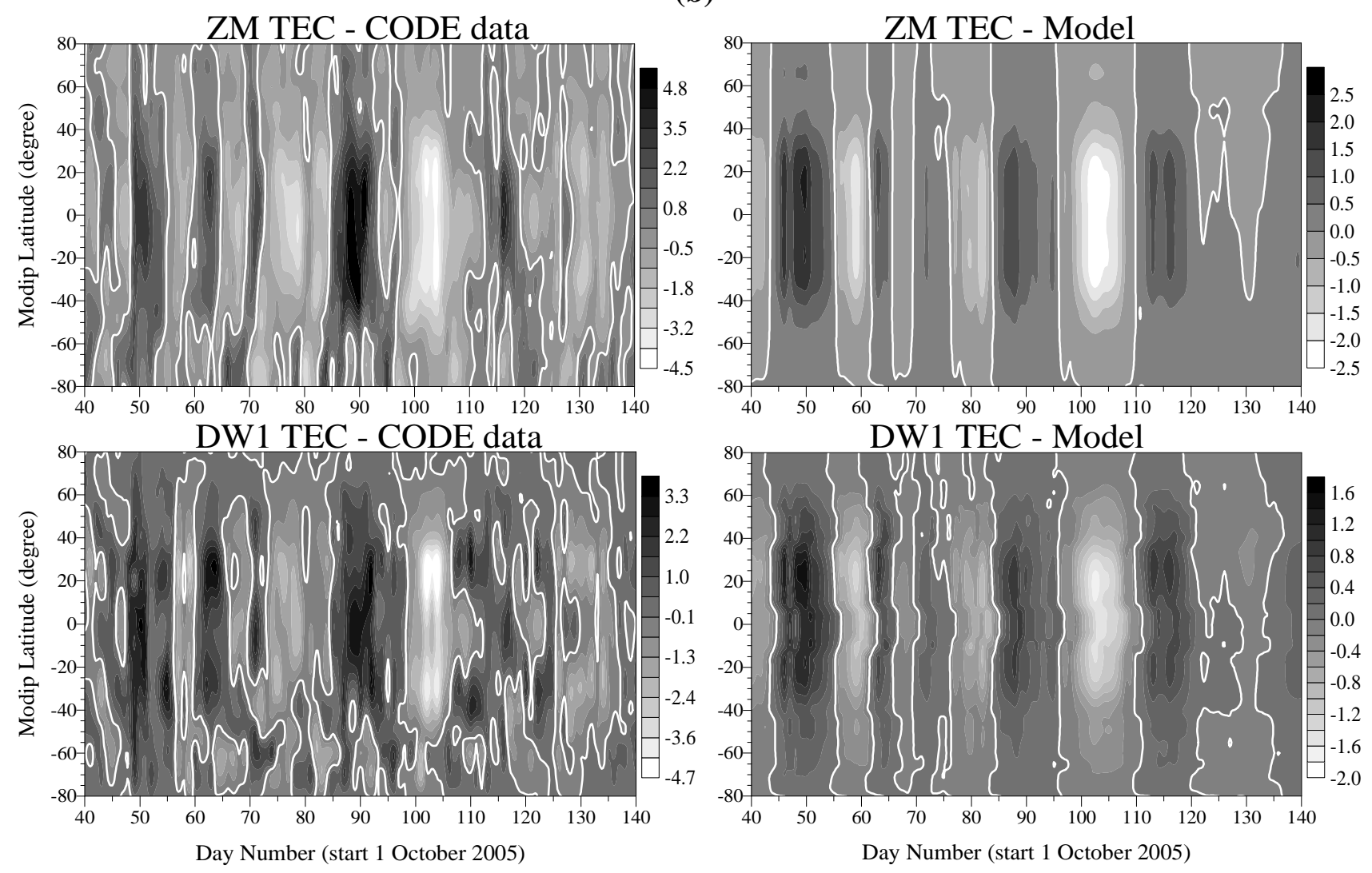

Figure 9 
(a)
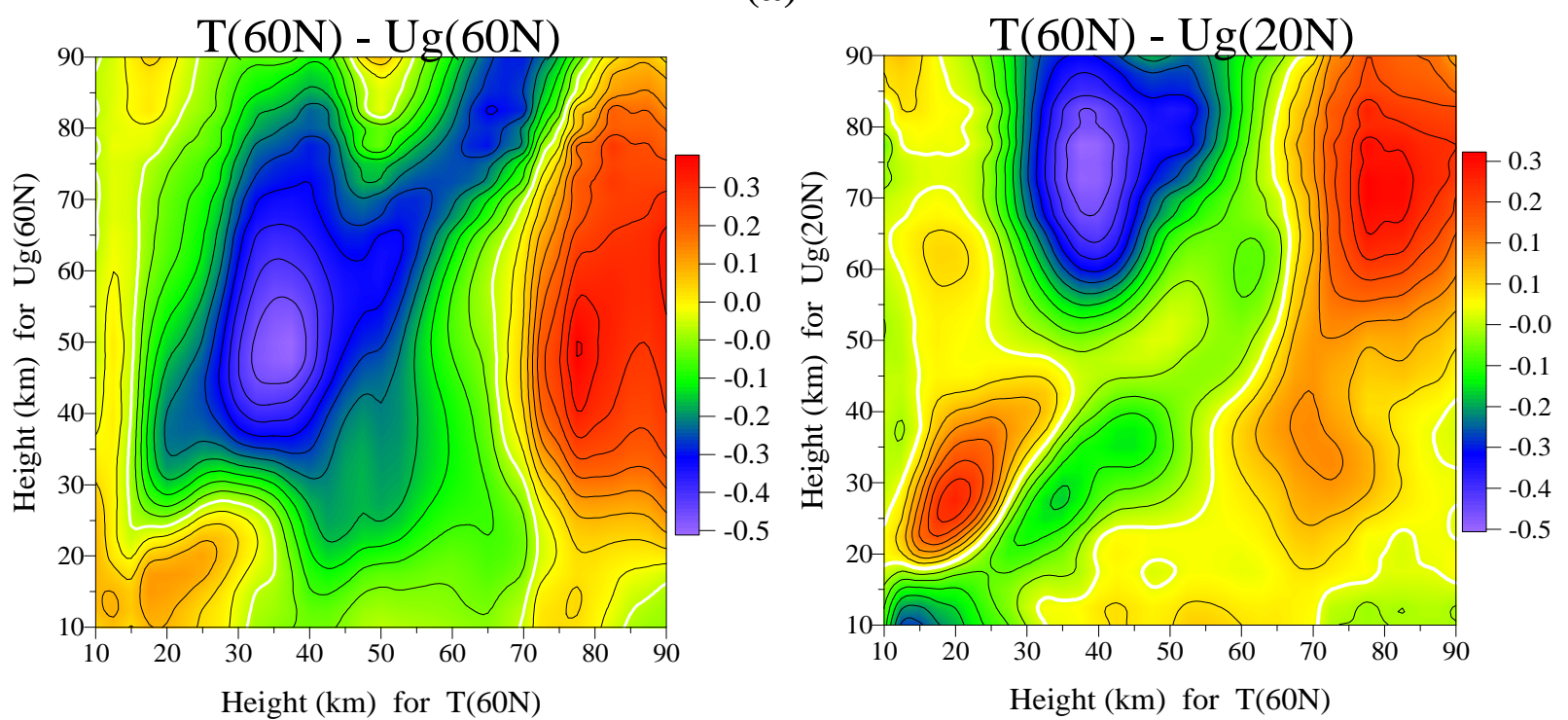

(b)

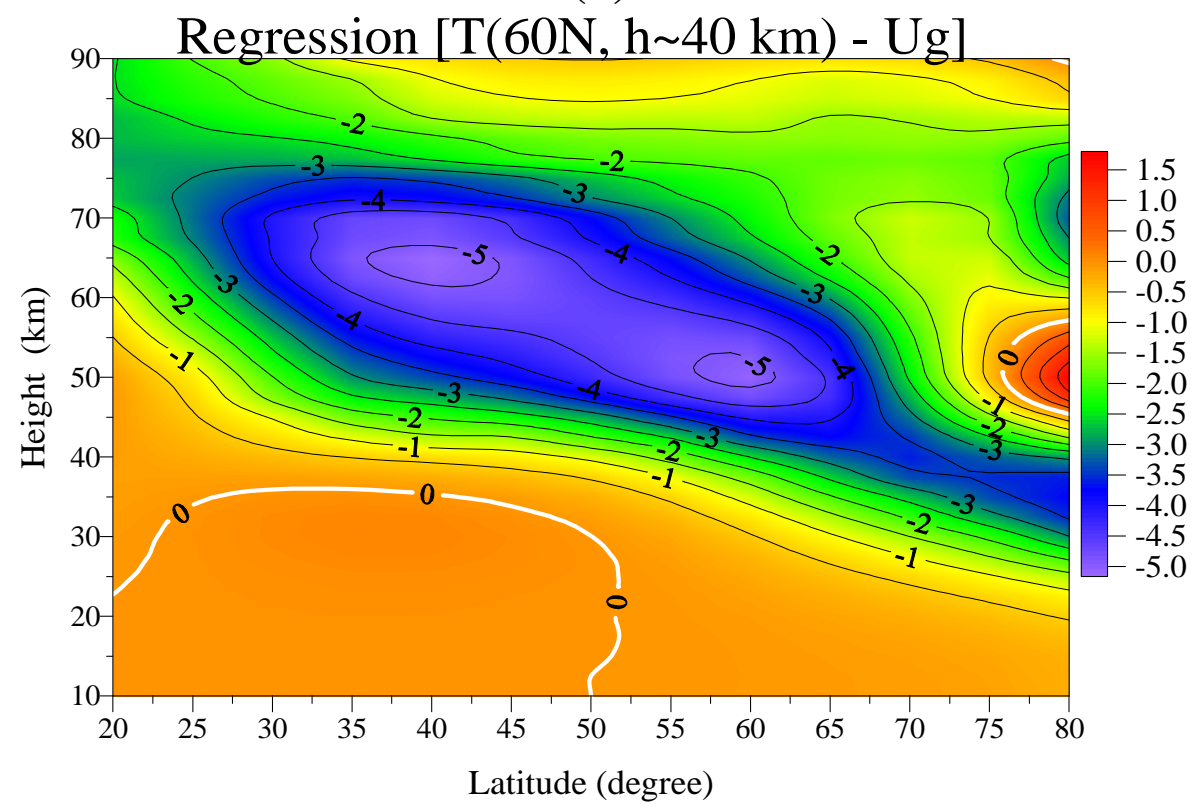

Figure 10 